NBER WORKING PAPER SERIES

\title{
SANITATION, DISEASE EXTERNALITIES, AND ANEMIA: EVIDENCE FROM NEPAL
}

\author{
Diane Coffey \\ Michael Geruso \\ Dean Spears \\ Working Paper 22940 \\ http://www.nber.org/papers/w22940 \\ NATIONAL BUREAU OF ECONOMIC RESEARCH \\ 1050 Massachusetts Avenue \\ Cambridge, MA 02138 \\ December 2016
}

We appreciate comments and suggestions from Harold Alderman, Oliver Cumming, Angus Deaton, Jeffrey Hammer, and Jean Humphrey. We thank seminar participants at Allahabad University, the Delhi School of Economics, and the Population Association of America 2014 annual meeting for helpful feedback. Research reported in this publication was directly supported by the Eunice Kennedy Shriver National Institute Of Child Health and Human Development of the National Institutes of Health under Award Number R03HD081209, administered through the University of Texas at Austin. Coffey and Spears also gratefully acknowledge a center grant for sanitation evidence from the Bill and Melinda Gates Foundation (OPP1125318) to r.i.c.e. r.i.c.e. is a 501(c)(3) non-profit research institute supported by donations and by research grants on sanitation and other topics. Geruso also gratefully acknowledges financial support from center grants 5 R24 HD042849 and 5 T32 HD007081 awarded to the Population Research Center at the University of Texas at Austin by the Eunice Kennedy Shriver National Institute of Child Health and Human Development. The content is solely the responsibility of the authors and does not necessarily represent the official views of the National Institutes of Health. This manuscript supersedes a previous draft by Diane Coffey entitled "Sanitation externalities, disease, and children's anemia," dated March, 2014. The views expressed herein are those of the authors and do not necessarily reflect the views of the National Bureau of Economic Research.

At least one co-author has disclosed a financial relationship of potential relevance for this research. Further information is available online at http://www.nber.org/papers/w22940.ack

NBER working papers are circulated for discussion and comment purposes. They have not been peer-reviewed or been subject to the review by the NBER Board of Directors that accompanies official NBER publications.

(C) 2016 by Diane Coffey, Michael Geruso, and Dean Spears. All rights reserved. Short sections of text, not to exceed two paragraphs, may be quoted without explicit permission provided that full credit, including $\odot$ notice, is given to the source. 
Sanitation, Disease Externalities, and Anemia: Evidence From Nepal

Diane Coffey, Michael Geruso, and Dean Spears

NBER Working Paper No. 22940

December 2016

JEL No. I15,J1,O1

\section{ABSTRACT}

Anemia impairs physical and cognitive development in children and reduces human capital accumulation. The prior economics literature has focused on the role of inadequate nutrition in causing anemia. This paper is the first to show that sanitation, a public good, significantly contributes to preventing anemia. We identify effects by exploiting rapid and differential improvement in sanitation across regions of Nepal between 2006 and 2011. Within regions over time, cohorts of children exposed to better community sanitation developed higher hemoglobin levels. Our results highlight a previously undocumented externality of open defecation, which is today practiced by over a billion people worldwide.

Diane Coffey

r.i.c.e.

472 Old Colchester Road

Amston, CT 06231

coffey@utexas.edu

Michael Geruso

University of Texas at Austin

Department of Economics

1 University Station C3100

Austin, TX 78712

and NBER

mike.geruso@austin.utexas.edu
Dean Spears

r.i.c.e.

472 Old Colchester Road

Amston, CT 06231

dean@ riceinstitute.org 


\section{Introduction}

Anemia is a widespread problem with serious health and economic consequences. Defined by low counts of red blood cells or low levels of hemoglobin in the bloodstream, anemia implies a reduced capacity for the blood to carry oxygen. In adults, it reduces productivity (Thomas et al., 2004) and is associated with higher maternal mortality (Rush, 2000). In children, it impairs physical and cognitive development directly (Grantham-McGregor and Ani, 2001; Ozier, 2015) and affects human capital accumulation via impacts on behaviors like school attendance (Bobonis, Miguel and Puri-Sharma, 2006). Globally, more than $40 \%$ of children have hemoglobin levels below the threshold for anemia. ${ }^{1}$ The problem is particularly severe in the developing world, as anemia is closely associated with inadequate nutrition.

Because of its damaging effects on human capital formation and productivity, anemia has attracted significant research and policy attention. Economic research in the area of preventing or reducing anemia has generally focused on (i) poor nutrition, and in particular iron deficiency (e.g., Bhattacharya, Currie and Haider, 2004; Thomas et al., 2004), and (ii) malaria (Sachs and Malaney, 2002), which is a parasitic infection that attacks the red blood cells. Nonetheless, there are reasons to believe that poor nutrition and malarial disease are not the only important causes of anemia. For one, international variation in anemia rates is not well explained by international variation in income (Alderman and Linnemayr, 2009). To the extent that income is a reasonable proxy for basic nutrition, this poses somewhat of a puzzle. Second, although it is well known that in sub-Saharan Africa malaria is a major cause of anemia, anemia rates are highest in South Asia, where malaria is far less prevalent.

In this paper, we propose a third broad cause of anemia that operates in addition to nutritional intake and malaria, and which has important (and different) implications for policy. We propose that poor local sanitation causes lower hemoglobin levels and higher rates of anemia in children. Following the recent literature (e.g., Guiteras, Levinsohn and Mobarak, 2015), we operationalize poor sanitation by measuring open defecation, which is defecation outside on the open ground, without the use of a toilet or latrine. Whereas nutritional intake is a behavior with purely private benefits, poor sanitation primarily constitutes an external harm: it spreads fecal pathogens across individuals, since these are transmitted by contact with the fecal matter that is left in the open. As we discuss

\footnotetext{
${ }^{1}$ See Stevens et al. (2013) for worldwide anemia rates.
} 
below, there is significant epidemiological evidence suggesting that sanitation could play an important role in determining anemia. Among other channels, the intestinal parasites and other infections spread by open defecation can affect the intestinal wall in ways that lead to decreased absorption of nutrients, including iron, vitamin B12 and folic acid (Rosenberg and Bowman, 1982; Nath, 2005), which are critical for the production of hemoglobin. If sanitation were indeed an important determinant of hemoglobin levels, its potential role in the worldwide, aggregate patterns of anemia would be staggering: more than a billion people (about $14 \%$ of the world's population) defecate in the open today.

Ours is the first paper to empirically link open defecation to anemia. Nevertheless, the possibility of such a link is suggested by a chain of evidence in a small body of prior work. With respect to the connection between open defecation and intestinal parasites, a randomized control trial in Indonesia that included toilet construction and behavior change interventions to discourage open defecation found evidence that reduced rates of open defecation were associated with reduced intestinal parasite infections (Cameron, Olivia and Shah, 2013). With respect to the connection between intestinal parasite infections and anemia, a randomized control trial among Kenyan children found that a single dose of intestinal parasite (deworming) medicine was as effective in improving hemoglobin levels as a daily supplement of 13 micronutrients including iron taken for eight months (Friis et al., 2003). ${ }^{2}$ Miguel and Kremer (2004) also provide experimental evidence that deworming reduces anemia in the Kenyan context. The clearest evidence to date suggesting that poor local sanitation may cause anemia is presented in Bleakley (2007), which studied the effects of a hookworm eradication campaign in the US South at the turn of the twentieth century. The eradication efforts included the construction and promotion of sanitary latrines. That paper found large effects on school attendance and later-life earnings for children exposed to the eradication campaign. The hypothesized mechanism was reduced anemia, but the historical data could not be used to provide direct evidence of an effect of the sanitary environment on blood hemoglobin levels. ${ }^{3}$

We examine the impact of sanitation on children's hemoglobin levels in the context of Nepal. Nepal is an ideal empirical setting for several reasons. First, Nepal has very little malaria, which

\footnotetext{
${ }^{2}$ Similarly, in a randomized control trial in India, Bobonis, Miguel and Puri-Sharma (2006) found that a combination of nutrient supplementation (iron and vitamin A) and deworming medications had a positive-though statistically insignificant - effect on hemoglobin levels. Bobonis, Miguel and Puri-Sharma (2006) was not designed to separately identify the effects of iron supplementation and intestinal parasite (deworming) medicine.

${ }^{3}$ Hookworms are spread by skin contact with human fecal matter. The eradication efforts featured a deworming campaign, and later, technical assistance in constructing sanitary latrines to arrest the cycle of reinfection.
} 
in other developing country contexts could be an important confounder when examining anemia. Second, the Nepal DHS surveys-unlike, for example, the Indian DHS or other Indian datasetshave collected blood hemoglobin measurements over multiple survey waves, and report geographic identifiers at a relatively disaggregated level, allowing us to create a geographic panel with anemia measures. ${ }^{4}$ Finally, Nepal has had relatively high rates of open defecation historically, but also rapid improvement in sanitation in the recent past. In 2006, about 50\% of Nepali households defecated in the open - that is, they reported using a bush, field, or no facility. By this measure, Nepali households faced among the worst sanitation environments in the world. The rates of open defecation in Nepal were worse, for example, than in most countries in sub-Saharan Africa at the time.

However, following the introduction of national government initiatives aimed at reducing open defecation, there was a rapid improvement in latrine and toilet use. By 2011, the fraction of households defecating in the open had declined to a national mean of $35 \%$, with significant variation in improvements across regions. The effective "exposure" of a locality to government-led sanitation efforts in the mid 2000s was heavily constrained by the then-current level of sanitation in each locality. Places with historically worse sanitation had a larger scope for improvement in level terms. For example, regions that were already open defecation free by 2006 could experience no further improvements, while regions with the highest open defecation rates (as high as $70 \%$ ) experienced the largest level changes (in excess of 30 percentage points) over our short panel.

We exploit the geographically heterogeneous sanitation improvements from 2006 to 2011 to identify impacts of poor sanitation on hemoglobin in difference-in-differences regressions. We find that cohorts of children exposed to better community sanitation developed higher hemoglobin levels. Controlling for own defecation practice, a 10 percentage point decrease in the fraction of neighbors who defecate in the open is associated with a $0.13 \mathrm{~g} / \mathrm{dL}$ increase in hemoglobin levels, or about $9 \%$ of a standard deviation. To put this effect size in context, interventions in the experimental nutrition literature, such as micronutrient supplementation (Friis et al., 2003), iron supplementation (Lind et al., 2003), and iron fortification in foods (Van Stuijvenberg et al., 1999), have effect sizes that range from $0.20 \mathrm{~g} / \mathrm{dL}$ to $0.41 \mathrm{~g} / \mathrm{dL}$. The effect sizes we estimate are consistent with the experimental evidence

\footnotetext{
${ }^{4}$ Although India would be a natural setting in which to examine the impact of sanitation on anemia, the Indian DHS has blood hemoglobin information only in 2005, and does not include district identifiers in that year. Other Indian datasets that would allow us to construct a geographic panel, including the the India Human Development Survey and the Indian District Level Health Survey, did not collect hemoglobin information. Therefore, we cannot exploit sanitation policy variation in India for identification as in Spears and Lamba (2015) or Spears (2012) or other natural experiments in the Indian context, as in Geruso and Spears (2015).
} 
on the efficacy of anti-intestinal parasite interventions by Friis et al. (2003), in which a single dose of deworming medicine increased hemoglobin by $0.21 \mathrm{~g} / \mathrm{dL}$. As we describe in greater detail below, the spread of intestinal worms via contact with fecal matter comprises just one of the channels by which the effects we find are likely to operate.

The parallel trends assumption underlying our difference-in-differences analysis is that regional variation in sanitation improvements was not correlated with other changes within regions over time that could independently affect hemoglobin levels. The list of potential confounding variables is somewhat narrowed by the extensive prior economic, epidemiological, and medical literature on the causes of anemia. Our data allow us to directly test for parallel trends in variables that span this small set of plausible confounding factors. We show that diet, the consumption of iron supplements, and the use of deworming treatments were not differentially trending in places with greater sanitation improvement. Further, we provide evidence that our results are not driven by a broader package of changes in the local physical infrastructure that were spuriously correlated with improvements in latrine availability.

The main contribution of our study is to advance the basic scientific understanding of the causes of anemia. Anemia has attracted significant attention as a human capital outcome in the US and the developing world (e.g., Bhattacharya, Currie and Haider, 2004; Miguel and Kremer, 2004; Thomas et al., 2004; Cohen and Dupas, 2010), though prior efforts by economists to identify the determinants of anemia (e.g., Thomas et al., 2004; Bobonis, Miguel and Puri-Sharma, 2006) have often focused on inputs constituting private goods. In particular, past experimental interventions have randomized whether an individual child received an iron supplement, fortified food, or deworming medicine. Our study is unique in investigating a public goods cause of anemia, and thus complements this existing literature. ${ }^{5}$ More broadly, we view our results as contributing to an expanding understanding of what constitutes nutrition. Anemia is typically labeled a "nutritional" outcome, but we show here that it is affected by a disease environment that impairs nutrient absorption, rather than affecting nutrient intake. In this way, our findings connect to the wider literature on the importance of nutrition during early childhood for human capital accumulation (e.g., Maluccio et al., 2009; Deaton, 2013),

\footnotetext{
${ }^{5}$ Miguel and Kremer (2004) is a related study that analyzes the effects of school-level deworming on child school attendance. The authors show that, due to positive treatment externalities, the impact of deworming medicine on school attendance is higher when entire schools, rather than individual children, are dewormed. Our paper differs in that we study open defecation, which is likely to affect hemoglobin through a variety of channels, including-but not limited to-worm infections, and because we study hemoglobin rather than schooling outcomes.
} 
and are consistent with recent work by Duh and Spears (2016) on the importance of considering net nutrition, rather than merely calorie intake. ${ }^{6}$

Our finding that the local sanitation environment is a public good affecting hemoglobin suggests new policy avenues for addressing anemia and raises new considerations for future research. One such policy implication is that reducing anemia in children can in part be accomplished by changing the health behaviors of community members (i.e., neighbors) who are neither children nor parents. Improving sanitation raises its own set of difficulties exactly because sanitation is a public good and therefore subject to inadequate private investment (Guiteras et al., 2014), suggesting a welfare-improving role for government. With respect to future research, our findings imply that any investigation of the role of open defecation in determining anemia requires variation that arises at the level of a neighborhood or region (as it does in our empirical analysis), rather than at the person-level. This suggests that the kind of cluster-randomized trials that have recently been fielded to examine other aspects of local sanitation (see, e.g. Guiteras, Levinsohn and Mobarak, 2015 and Clasen et al., 2015) are also the right approach for future experimental work that builds on our findings regarding anemia.

Finally, this paper contributes to a growing literature concerned with the adverse health and human capital consequences of poor sanitation in the developing world. Open defecation, in particular, has attracted significant policy attention and NGO investment in recent years for reasons unrelated to anemia. Our findings on children's hemoglobin strengthen the rationale for such investments, and may play a role in explaining some of the recent findings in the literature. For example, Spears and Lamba (2015) find that exposure to open defecation negatively impacts child cognitive function, which is an outcome known to be affected by anemia (Stoltzfus et al., 1997).

The remainder of the paper is organized as follows. Section 2 discusses the known causes of anemia and reviews the existing epidemiological evidence of a channel from poor sanitation to lower hemoglobin. Section 3 presents some new stylized facts from international comparisons that are intended to motivate our main analysis. Section 4 describes our data, identifying variation, and empirical strategy. Section 5 reports results, and Section 6 traces out the significance and policy relevance of our findings. Section 7 concludes.

\footnotetext{
${ }^{6}$ Our study also connects to a wide literature on the role of water, sanitation, and disease environment in driving health and human capital accumulation in the developing world and the historical US. See, for example, Cutler and Miller (2005); Watson (2006); Spears (2012)).
} 


\section{Background on Anemia and Sanitation}

Hemoglobin is a protein which resides in red blood cells, and which binds to iron in order to attract oxygen and carry it throughout the body. Iron deficiency anemia is defined by hemoglobin below a threshold level. There are several known causes of low hemoglobin. These involve either too little production or too much destruction of hemoglobin.

Poor diets, particularly among young children, are an often-cited cause of anemia in developing countries (Yip and Ramakrishnan, 2002; Tolentino and Friedman, 2007). Although a major cause of low hemoglobin production is iron deficiency in the diet, low hemoglobin can can also be caused by lack of vitamin B12 and folic acid, two nutrients necessary for the production of red blood cells. The late introduction of solid foods in infants and diets containing inadequate amounts of these essential nutrients are both important contributors to low hemoglobin in South Asia (Menon, 2012), the region of the developing world we study here. ${ }^{7}$

Malaria is another important cause of anemia, particularly in sub-Saharan Africa. The disease is transmitted by a mosquito bite, during which a parasitic protozoa carried by the mosquito enters the person's bloodstream. The malaria parasite attacks red blood cells, which are in turn attacked by the host's immune system. This destruction of red blood cells leads to anemia. (The protozoan malaria parasite is significantly different in form, life cycle, and symptomatic effects from the intestinal worms we discuss below, which are transmitted by contact with human excreta.)

How could poor sanitation affect anemia? There are two plausible channels. The first is related to intestinal parasites and the second is a condition known as environmental enteropathy. ${ }^{8}$ Our study does not attempt to distinguish between these two epidemiological pathways, as both are consistent with an impact of poor sanitation, and both are likely to be operating simultaneously.

Intestinal parasites are known to cause anemia by causing blood loss in the stool, lack of appetite, increased motility of food through the intestine, and competition for nutrients. ${ }^{9}$ Intestinal parasites also cause damage to the intestinal wall that leads to decreased absorption of nutrients, including iron, vitamin B12 and folic acid (Rosenberg and Bowman, 1982). It has long been known that open defecation spreads intestinal parasites; Cairncross (2003) cites research from the 1930s that describes

\footnotetext{
${ }^{7}$ A strict vegetarian diet, containing no animal proteins, would be lacking in vitamin B12.

${ }^{8}$ It is also possible that intestinal diseases spread by open defecation could affect pregnant women, and lead them to pass low iron stores on to their babies. See Allen (1997).

${ }^{9}$ Intestinal parasites (helminths) are also commonly called parasitic worms or intestinal worms. Deworming medicine means medicines like albendazole.
} 
how variation in community latrine use in the southern United States predicted parasite infections in children. ${ }^{10}$

The second pathway from open defecation to hemoglobin levels is environmental enteropathy, known as tropical sprue in an older medical literature. It is a disease which alters the lining of the intestine and inhibits absorption of calories and nutrients. Although the link between open defecation and enteropathy is less well understood than the link between open defecation and intestinal worms, it is hypothesized that open defecation exposes people to the kinds of bacteria that, when ingested in large quantities, lead to decreased absorption of micronutrients necessary for the production of hemoglobin (see Walker, 2003, Nath, 2005 and Humphrey, 2009). ${ }^{11}$ Medical researchers have hypothesized a link between enteropathy and anemia as long ago as the 1920s (Baumgartner and Smith, 1927).

\section{Stylized Facts from International Comparisons}

To motivate the our econometric analysis below, we begin in Figure 1 by documenting some crosscountry summary statistics relating sanitation to anemia. To our knowledge, ours is the first study to document these patterns, even cross-sectionally.

Data on anemia and open defecation used in the figure come from 81 Demographic and Health Surveys (DHS), covering 45 countries in sub-Saharan Africa, Latin America, Europe, and Asia. The country $\times$ years that make up individual observations are listed in Appendix Table A1. The DHS are nationally representative surveys that collect information on health behaviors and outcomes of household members, including data on toilet use. In our data, if a respondent household reports using a "bush, field, or no facility," the household is coded as defecating in the open. Following Spears (2013) we capture the sanitation environment to which a child is exposed by calculating the fraction of households that defecate in the open. The greater the fraction of households that do not use a toilet or latrine, the greater the frequency with which a child comes into contact with germs or parasites transmitted by feces.

Observations in Figure 1 are means from surveys (countries $\times$ years), and we include every

\footnotetext{
${ }^{10}$ Children infected with parasites pass them through their bowel movements to the soil; many parasite eggs can live in the soil until they come into contact with new hosts, such as other children who come to the same places to defecate in the open.

${ }^{11}$ It has been documented that enteropathy affects the absorption of vitamin B12 and folic acid, two essential nutrients for the production of hemoglobin (Nath, 2005).
} 
survey for which data on children's hemoglobin was measured. The DHS measures hemoglobin using the HemoCue ${ }^{\circledR}$ method, in which a surveyor introduces a drop of blood from the respondent's finger into a portable device that reports the respondent's hemoglobin level in the field. ${ }^{12}$

In Panel A of Figure 1, we plot the unconditional relationship between the average hemoglobin level of children and the mean open defecation rate in the country. We restrict attention to children aged 6 to 35 months, as this was the common age range for which hemoglobin data was recorded across the 81 DHS surveys represented in the figure. The size of markers is proportional to country population, and many countries appear twice in the scatterplot for different survey years. The figure also plots a regression line corresponding to the population-weighted OLS coefficient of open defecation on hemoglobin. The plot shows a clear association in which more open defecation (i.e., worse sanitation) predicts lower hemoglobin levels of children.

In Panel B, we modify the horizontal axis so that it measures the log of open defecation per square kilometer, following a recent literature showing that the risk of transmitting pathogens via open defecation is increasing in population density (Spears, 2013; Hathi et al., 2014). Data on total land area and population, which are used to construct the measure of open defecation per square kilometer, come from the Penn World Tables. The clear negative relationship continues to hold. While the slopes are not directly comparable between Panels A and B since the horizontal axes are different, the overall decline in hemoglobin levels between observations with the best sanitation (leftmost points) and worst sanitation (rightmost points) are similar across the two panels.

A natural question in this context is whether the places with worse sanitation are merely worse in other ways that would independently predict anemia. In particular, malaria incidence, which impacts anemia, may be worse in countries where the sanitation environment is worse. And nutritional intake, which is the leading known cause of anemia, may be worse where sanitation is worse, since both are correlated with income. In panels C and D of Figure 1, we control for malaria incidence using national malaria rates constructed by Korenromp (2005), and we control for GDP per capita using data from the Penn World Tables. ${ }^{13}$ In Panels E and F of Figure 1, we additionally control for available diet information. The diet module is only available in a subset of the surveys (35 DHS country $\times$ years). For these surveys, respondents provide information about the types and amounts

\footnotetext{
${ }^{12}$ See Measure DHS (2013) for more information about collection of hemoglobin data in the field. Kapoor et al. (2002) compares the HemoCue $(1)$ method to other methods of testing hemoglobin in India. This paper uses the hemoglobin measurement that is unadjusted for altitude.

${ }^{13}$ The details of the GDP and malaria data construction are described in Appendix A.1.
} 
of foods consumed by their young children over the last 24 hours. The dietary controls include an indicator for the child consuming meat and eggs in the last 24 hours, an indicator for the child consuming fruits or vegetables in the last 24 hours, and a dietary diversity measure, defined as the number of different kinds of foods consumed by the child in the last 24 hours. ${ }^{14}$ To display scatter plots that use the various control sets, we first separately regress hemoglobin and open defecation on the indicated controls. We then plot the residuals from those two regressions against each other. The relationship between sanitation and anemia is, in fact, stronger after the inclusion of controls for malaria and GDP per capita, as indicated by the R-squared that is reported in the upper left of each panel. The addition of the dietary controls in Panels E and F generate residual scatterplots that continue to show a clear relationship between OD and blood hemoglobin levels. Panel F is particularly striking, with observations tightly clustered around the regression line and the highest R-squared of any panel.

Although Figure 1 is intended only to provide motivation for the econometric analysis below, the patterns it reveals are consistent with a previous finding in the literature that international variation in anemia rates is not well explained by international variation in income (Alderman and Linnemayr, 2009). The patterns are also consistent with the fact that although malaria is less prevalent in South Asia than in sub-Saharan Africa, rates of anemia in South Asian countries often exceed those of subSaharan African countries. In South Asia, open defecation is more prevalent.

In summary, the cross-country comparison reveals an interesting and previously undocumented pattern. Poor sanitation strongly predicts low hemoglobin, both unconditionally, and controlling for income, measures of food intake, and malaria incidence. The remainder of the paper investigates a causal relationship, using variation in open defecation that is plausibly exogenous to hemoglobin levels.

\section{Data and Empirical Framework}

We investigate the hypothesized link between sanitation and anemia using data from Nepal. Nepal ranks among the worst sanitation environments in the world. As recently as 2006, half of Nepali households disposed of excreta in the open, without the use of a toilet or latrine. But sanitation

\footnotetext{
${ }^{14}$ For reference, Appendix Figure A1 plots the unconditional relationship between each of these variables and hemoglobin levels. The figure also shows the unconditional correlation between country malaria rates and hemoglobin levels.
} 
in Nepal has improved rapidly since that time, following sanitation initiatives launched by Nepal's central government in the mid-2000s. The DHS data show a 13 percentage point decline in open defecation at the national level between 2006 and 2011. Nepal's poor baseline sanitation, rapid improvement, and very low rates of malaria, make it an ideal empirical setting for our study.

\subsection{Data}

The data used in our main analysis come from the 2006 and 2011 Demographic and Health Surveys (DHS) of Nepal. ${ }^{15}$ As described above, the DHS surveys are designed to be nationally representative. In addition to the variables used to construct Figure 1, mothers in these Nepal DHS rounds report on whether they took iron supplements during their most recent pregnancy and on whether each child in the sample has taken intestinal parasite medication in the last six months.

Typically, anemia is defined by hemoglobin levels below some threshold value. The World Health Organization (WHO) sets the hemoglobin concentration threshold at $11 \mathrm{~g} / \mathrm{dL}$ and $7 \mathrm{~g} / \mathrm{dL}$ for anemia and severe anemia, respectively, though various researchers and medical bodies may set alternative cutoffs. ${ }^{16}$ In order to maximize power and avoid sensitivity to the choice of threshold, we use the entire continuous range of hemoglobin concentration in our main results, though we also report specifications in which the dependent variables are indicators for various anemia thresholds.

From the measures of open defecation, we generate variables capturing the mean open defecation at the level of a neighborhood or region, depending on the analysis. Neighborhoods are reflected in the data by primary sampling units (PSUs), which are composed of approximately 100 to 200 colocated households. In rural areas these PSUs may be whole villages. In urban areas, the PSUs are defined by blocks of households. Because the DHS does not re-interview the same PSUs in different survey waves, in most specifications we aggregate location data to the smallest geographic unit for which it is possible to construct a panel in our data. The survey identifies 13 geographic areas in Nepal. We interact the urban indicator with indicators for each of 13 areas to create 25 "region" indicators, which we exploit in our difference-in-differences regressions. ${ }^{17}$

In Table 1 we provide summary statistics for our analysis samples, stratified by survey year. Ob-

\footnotetext{
${ }^{15}$ In both the 2005/2006 and the 2010/2011 rounds, surveys were conducted between October and April.

${ }^{16}$ This WHO standard applies to children 6 to 60 months of age.

${ }^{17}$ There are 25 , rather than 26 , regions because the western mountain region contains no urban areas. The designation of localities as urban and rural was unchanged between survey rounds.
} 
servations in the table are children, corresponding to the level of analysis in the regressions below. ${ }^{18}$ Hemoglobin data were collected for all children 6 to 59 months old in the 2006 survey, but only for a random subsample of $50 \%$ of children in this age range in the 2011 survey. Within the main analysis sample $(\mathrm{N}=6,464)$ that contains hemoglobin data and the main control set, dietary information was collected for a smaller subsample $(\mathrm{N}=4,348)$ that targeted the younger children in each household. Similarly, information on mother's use of iron supplementation during pregnancy was only recorded with respect to the most recent pregnancy for each mother, leading to a somewhat smaller sample size $(\mathrm{N}=4,720)$ relative to the main analysis sample. Table 1 presents summary statastics for the main ("full") sample and for the dietary module ("food") subsample. For completeness, Appendix Table A2 repeats the summary statistics for the subsample of children for which we observe whether the mother took iron during pregnancy.

Table 1 shows that the use of intestinal parasite medicine was fairly stable over the 2006 to 2011 period. Over the same period there was a large decline in open defecation. Toilet and latrine use (one minus open defecation) climbed by an average of 13 percentage points nationally. Children's consumption of meat and eggs was unchanged over time, though fruit and vegetable consumption declined nationally, suggesting a relative deficit in some nutrients critical to hemoglobin production. Dietary diversity, defined as the number of kinds of foods (meat and eggs, plant protein, fruits and vegetables, starches, and dairy) consumed, also declined. This worsening of food intake, trending opposite to the improved sanitation, may account for the essentially unchanged average level of hemoglobin between the 2006 and 2011 survey rounds, though the stable national average masks significant regional variation over time. In terms of general economic and infrastructure development, household electrification and access to improved water sources also significantly increased over this period.

\subsection{Identifying Variation}

Between the 2006 and 2011 rounds of the Nepal DHS there was a large reduction in open defecation. Importantly for our study, this improvement varied significantly across the 25 regions described above. To illustrate the difference-in-differences variation that we exploit for identification, Figure 2

\footnotetext{
${ }^{18}$ Note that the sample in each year consists of children under 5 , so the data regarding literacy and education applies only to relatively recent mothers who will be younger on average. This feature of the data, combined with rapid improvements to education in Nepal over the relevant time period, result in significant differences in reported maternal education and literacy rates between the two survey rounds.
} 
shows how open defecation changed within regions over time. Panel A of Figure 2 plots the improvement in sanitation (one minus the mean open defecation rate) for rural areas. Panel B repeats the plot for urban areas. Colors correspond to the sanitation improvement, with darker red indicating less improvement, and darker green indicating more improvement.

Regional changes in the fraction of households practicing open defecation $\left(\overline{O D}_{r}\right)$ ranged from as little as zero to more than a 30 percentage point reduction in just 5 years. To put the size of this decline in context: India, which has similarly poor sanitation and has experienced fast economic growth over the last two decades, reduced open defecation by only about 1 percentage point per year between 2001 and 2011 (Government of India, 2011).

While it is not the goal of this paper to evaluate any particular policy—or even to catalogue the determinants of open defecation in Nepal over our study period-two facts are relevant for understanding the panel variation we exploit. First, beginning in the mid-2000s, policy attention by Nepal's central government turned more significantly towards sanitation. It is likely that this policy priority change and the resulting investment both drove changes in demand for latrines among Nepalis and was also reflecting changing national attitudes. Second, the effective "exposure" of a locality to government-led sanitation activities at the national level was heavily constrained by the current level of sanitation development in the locality. Places with historically worse sanitation had a larger scope for improvement in level terms.

The relevant policy changes originated at the national level in Nepal's Department of Water Supply and Sewerage, which in 2004 began launching initiatives aimed at improving sanitation. New National Guidelines for Hygiene and Sanitation Promotion were announced in 2005. At the time, Nepal's government had made a commitment to decentralizing the administration of government functions. In accordance with that broader policy commitment across areas of government, responsibility for determining the details of implementing sanitation policy rested with individual Village Development Committees and District Development Committees. ${ }^{19}$ Though there is no census of the local programs developed during this timeframe, activities included various subsidy programs for toilet construction as well as marketing campaigns aimed at increasing demand for toilets and latrines. $^{20}$

\footnotetext{
${ }^{19}$ Funding nonetheless originated at the national level. See Tayler, Scott and Shrestha (2005) for more details.

${ }^{20}$ Because of the decentralized approach, while the overall goal of reducing open defecation was a national priority, initiatives undertaken by these local authorities varied significantly in an attempt to tailor approaches to local needs and local behavioral norms. For example, in some places local campaigns consisted of encouraging children to use whistles to
} 
With respect to an area's "exposure" to national changes, it is plausible that national resources devoted toward curbing open defecation had greater scope for impact in places where the problem was more severe. In the extreme this was certainly true: in the case of zero open defecation at baseline (true for one urban region), there is was no room to improve further and there was consequently no significant change in open defecation over the 2006 to 2011 period. In contrast, in regions with the worst sanitation in 2006 (with open defecation rates as high as 70\%), open defecation levels declined by around 30 percentage points. This type of variation is similar to that used in a wide range of studies that identify impacts of national programs by generating a potential exposure measure that varies across geography (e.g., Finkelstein, 2007). ${ }^{21}$ In a study related to ours, Bleakley (2007) exploited geographic variation in the pre-treatment hookworm infection rate in regions of the US South to identify effects of a deworming campaign on human capital outcomes. While the hookworm campaign "treatment" was similar across areas, effective exposure was greater where the pre-program infection rate was higher.

Figure 3 demonstrates the idea in our setting, plotting the change in regional open defecation from 2006 to 2011 on the vertical axes against the 2006 level along the horizontal axes. Rural regions are plotted as scatter points in Panel A and urban regions are in Panel B. Sanitation improved essentially everywhere-in 22 out of the 24 regions with non-zero baseline open defecation. But both panels show that such reductions were larger in regions with higher levels of open defecation in 2006. Regressions corresponding to the figure in Appendix Table A3 confirm the statistical significance of the relationship at $p<.01$. In fact, the estimated slopes in the two panels are numerically identical at -0.45 . Therefore, without discounting the notion that the details of local policies mattered in many ways, we note that the regional variation in improvement between the survey rounds appears to be strongly determined by the baseline level of sanitation in $2006{ }^{22}$

Given the standard parallel trends assumption underlying our difference-in-differences analysis, it is important for us to demonstrate that the places with greater scope for sanitation improvement (i.e., greater "exposure" to the overall national sanitation improvement trend) were not differentially

call out people as they practiced open defecation. In other localities, access to certain government services was restricted until household members produced verification of latrine/toilet ownership. Additional anecdotal evidence is reported in Knight (2014).

${ }^{21}$ Finkelstein (2007) evaluates the impact of the introduction of Medicare in the US by exploiting heterogeneity across regions in the population share of the elderly.

${ }^{22}$ If the negative relationship in Figure 3 were driven simply by measurement error, such error should not be correlated with the regional change in our outcome of interest, hemoglobin levels. 
trending along other variables that might independently affect hemoglobin. Because the previous medical science points to nutrition, iron supplementation, and deworming as the known determinants of low hemoglobin, non-parallel trends in any of these three health inputs would be of particular concern. Fortunately, the DHS data can be used to provide direct evidence on each of these, and we investigate below whether patterns in these other health inputs where trending differentially in places that experienced the greatest improvements in sanitation. Here, we begin by noting that Figure 2 shows that improvements were not limited to low-lying regions (on the southern, Indian border) or mountainous regions (on the northern, Chinese border). Nor were improvements concentrated in contiguous areas of the country. Interestingly, there also appears to be no positive association between improvements in the rural and urban areas of the same regions: the color pattern of improvement in rural places (Panel A) is not paralleled in the urban places (Panel B) of the same geographic areas.

\subsection{Empirical Framework}

We organize our analysis at the level of the child, including as observations all children for whom hemoglobin was measured (children aged six months to five years). We regress hemoglobin concentration $(\mathrm{Hb})$ on the mean open defecation at the regional level $\left(\overline{O D}_{r t}\right)$ :

$$
H b_{i r t}=\beta_{1} \overline{O D}_{r t}+\beta_{2} O D_{i r t}+\alpha_{2011}+\sum_{r \in R} \alpha_{r}+f\left(X_{i r t}\right)+\epsilon_{i r t}
$$

Here, $i$ indexes children, $r$ indexes the regions over which we construct our panel, and $t$ indexes the DHS two survey rounds. The dependent variable $H b_{i p r t}$ is a continuous variable for blood hemoglobin concentration. $O D_{\text {iprt }}$ controls for whether the child's own household defecates in the open. This ensures that we are identifying external effects of local sanitation. We additionally control for a variety of person, household, and region-level characteristics in $f\left(X_{\text {iprt }}\right)$ to demonstrate robustness. These are described in more detail below. Fixed effects for survey round $\left(\alpha_{t}\right)$ and fixed effects for each of 25 regions $\left(\alpha_{r}\right)$ control for all common time trends and any place-specific characteristics that could otherwise confound results. The coefficient of interest, $\beta_{1}$, identifies the impact of a change in the mean of regional open defecation on childrens' hemoglobin levels.

In Eq. 1, we have aggregated the sanitation environment measure $(\overline{O D})$ up to the level of the 
region so that we can exploit region fixed effects. The alternative approach of disaggregating the locality data further and including neighborhood fixed effects is not possible here because the DHS sampling scheme did not re-interview in the same neighborhoods in the 2006 and 2011 rounds.

\section{Results}

\subsection{Main Findings}

We present the main regression results in Table 2, where the dependent variable across all columns is hemoglobin in children aged 6 to 59 months. The negative coefficient estimates in Table 2 show that improvements in sanitation-i.e. lower rates of open defecation-are associated with higher concentrations of hemoglobin in children. Point estimates are larger in the difference-in-differences than in the cross-sectional OLS regressions, though not statistically different. ${ }^{23}$

Columns 1 through 3 estimate the coefficient on $\overline{O D}_{r t}$ from Eq. 1 using pooled cross sectional data. Columns 4 through 6 add fixed effects for the 25 regions defined by geographic area interacted with urban. Adding region fixed effects changes these OLS regressions from a pooled cross sectional analysis to a difference-in-differences analysis, identified within regions over time. Regions with smaller or no improvements in sanitation implicitly serve to control for common time trends.

All columns control for survey round fixed effects, region indicators, and a complete set of 108 age-in-month $\times$ sex indicators to flexibly adjust for any biological differences in hemoglobin by age and sex. The control for "own OD" indicates whether the child's own household practices open defecation. ${ }^{24}$ Economic controls include indicators for 5 household assets asked about in both survey rounds, an indicator for household electricity, and controls for the quality of the child's dwelling, including the materials used in construction of the roof, walls, and floor. ${ }^{25}$ Mother's education controls

\footnotetext{
${ }^{23}$ In Appendix Section A.2 we present additional results from a complementary IV strategy that exploits the same source of variation as the difference-in-differences results in Table 2, but does so by instrumenting for PSU-level sanitation $\left(\overline{O D}_{\text {prt }}^{P S U}\right)$ with region $\times$ survey round variation.

${ }^{24}$ It is yet unknown whether contact with one's own feces is an important driver of sanitation-related health outcomes relative to the size of the public good impacts of sanitation, though some helminths including hookworm have a lifecycle that can exploit self re-infection. Nor is it known whether own OD significantly interacts with neighborhood OD to affect health, though Geruso and Spears (2015) provide some suggestive evidence against the interaction hypothesis. It is plausible that the specifications in Table 2 that control for own OD (columns 2, 3, 5, and 6) may over-control, leading to underestimates of the effects of improved sanitation. Indeed, these specifications do reveal smaller coefficients than in columns 1 and 4 of Table 2, which do not control for own OD, or compared to the results in Table 3 that aggregate to regional means and therefore do not control for own OD.

${ }^{25}$ These dwelling controls include indicators for type of wall materials (9 categories), roof materials (8 categories), and floor materials (6 categories) that make up the child's dwelling.
} 
include an indicator for literacy and indicators for levels of educational attainment (4 categories). "Parasite medicine" is an indicator for the child's consumption of intestinal parasite (deworming) medication within the last six months. Regional controls add time-varying region characteristics that are not absorbed by the regional fixed effects. These include mean household electrification and mean household access to protected/improved water sources within each region $\times$ year. ${ }^{26}$ The inclusion of economic controls, mother characteristics, medicine controls, and time-varying region-level controls has only minor effects on point estimates, indicating that our regressors of interest are not strongly correlated with these variables.

The mean reduction in open defecation nationally was on the order of a 10 percentage point decline. A coefficient of -1.27 on neighborhood level OD (col 6) indicates that a 10 percentage point reduction in the fraction of neighbors defecating in the open yields an improvement in hemoglobin of $0.127 \mathrm{~g} / \mathrm{dL}$, or about $9 \%$ of a standard deviation. To put this effect size in context, interventions such as daily micronutrient supplementation (Friis et al., 2003), iron supplementation (Lind et al., 2003), fortification (Van Stuijvenberg et al., 1999), and treating for parasites (Friis et al., 2003; TaylorRobinson et al., 2012) have effect sizes that range from $0.20 \mathrm{~g} / \mathrm{dL}$ to $0.40 \mathrm{~g} / \mathrm{dL}$.

Thus, the sanitation-hemoglobin effect is large, though not implausibly so. Recall that one of the two channels by which we hypothesize poor sanitation may impact hemoglobin is via intestinal worms, which are spread by skin contact with human fecal matter. In a double-blind randomized control trial in Kenya, Friis et al. (2003) find that a single dose of deworming medicine generated an increase in hemoglobin of $0.21 \mathrm{~g} / \mathrm{dL}$ measured eight months after its administration, an effect similar in size to that from an alternative treatment arm of the same study that administered daily supplements of 13 micronutrients (including iron) for eight months.

Standard errors in parentheses are clustered at the PSU-level across all columns. Because the difference-in-differences analysis uses variation in mean open defecation at the level of the regionby-year, we also investigate alternative clustering at the region-by-year level. The exercise, which requires a special asymptotic refinement due to the small number of clusters (see, e.g., Cameron, Gelbach and Miller, 2008 and Cameron and Miller, 2015), is described in Appendix Section A.3. Results from several alternative clustering schemes are tabulated in Appendix Table A4, which shows that the statistical significance of the results is robust to even the most aggregated level of clustering (25

\footnotetext{
${ }^{26}$ Improved water sources include piped water, protected wells, and protected springs.
} 
regions) and even after performing the proper asymptotic refinement (via Wild Cluster Bootstrapping).

For completeness, in Appendix Table A5 we report on alternative specifications that re-estimate our main results in Table 2 using various thresholds for anemia as the dependent variables rather than the continuous hemoglobin measure. The anemia thresholds that constitute the dependent variables correspond to the World Health Organization standards for mild $(<11 \mathrm{~g} / \mathrm{dL})$, moderate $(<10 \mathrm{~g} / \mathrm{dL})$, and severe $(<7 \mathrm{~g} / \mathrm{dL})$ anemia. The binary outcome measures generate relatively large confidence intervals, ${ }^{27}$ though for anemia defined as moderate or worse, effects are statistically significant at the $5 \%$ level in both the cross-sectional and difference-in-differences specifications.

Finally, for robustness, we also report on an alternative IV estimation strategy in Table 3 that aggregates up to the level of the region and exploits the variation displayed in Figure 3, in which regions with worse starting points had greater scope for rapid improvement. For these regressions, we define an Exposure variable equal to the 2006 level of open defecation. We aggregate all data to the region, and take first differences from 2006 to 2011 for our dependent and independent variables of interest, denoting changes with $\Delta$. This results in 25 observations. We run the following regression, which instruments the within-region sanitation change, $\Delta \overline{O D}_{r}$, with region-specific exposure to national changes:

$$
\begin{array}{r}
\Delta \overline{H b}_{r}=\beta_{1}{\widehat{\Delta \overline{O D}_{r}}}+\epsilon_{r}, \\
{\widehat{\Delta \overline{O D}_{r}}}_{r}=\theta \text { Exposure }_{r}+\mu_{r} .
\end{array}
$$

This specification has the advantage of identifying estimates using only variation in sanitation improvement over time that is predicted by the 2006 level within the region. This is the variation depicted in Figure 3. ${ }^{28}$ An additional advantage of the regression in Eq. 2 is that it is not subject to the small number of clusters issue discussed above. Robust standard errors are consistent here without asymptotic refinement. ${ }^{29}$ Of course, this method has the drawback of not allowing inclusion of individual-level covariates and of estimating the coefficient of interest off of just 25 observations. Nonetheless, the results in Table 3 align closely with the main results in Table 2.

\footnotetext{
${ }^{27}$ See Spears, Ghosh and Cumming (2013) for an illustration of the statistical power loss resulting when height is dichotomized at a "stunting" threshold in lieu of using the continuous measure.

${ }^{28}$ The first stage is reported in Appendix Table A3.

${ }^{29}$ Intuitively, these 25-observation regressions coarsen the data to the maximal possible extent.
} 
In the context of this regression, it is also important to note that the Exposure variable is not merely capturing a mean reversion pattern. Mean reversion would occur if regions experienced a simultaneous negative shock to both children's hemoglobin and sanitation prior to the 2006 DHS survey round, and then rebounded by the 2011 round. In contrast to this type of pattern, changes in sanitation tend to be unidirectional (towards improvement). We verify the unidirectional nature of sanitation changes in our setting using an earlier 2001 round of the Nepal DHS. This earlier round contains data on open defecation for 23 of our 25 regions, but pre-dates the measurement of hemoglobin by the DHS. Sanitation improved within most regions (76\%) between 2001 and our base year, 2006, just as it did between 2006 and 2011 (in 88\% of regions), which is inconsistent with mean reversion. In the few regions where sanitation worsened from 2001 to 2006, the change was relatively small. In addition, there was no significant correlation between the 2001/2006 change in open defecation $\left(\Delta \overline{O D}_{r, 2000 / 2006}\right)$ and the 2006/2011 change $\left(\Delta \overline{O D}_{r, 2006 / 2011}\right)$, contrary to mean reversion. Nor was there a significant correlation between indicators for the signs of these changes-i.e., a region experiencing a sanitation decline from 2001 to 2006 was not more likely to experience a sanitation improvement from 2006 to 2011. Similarly, creating two rankings of regions according to their 2001/2006 changes and their 2006/2011 changes and performing the Spearman's test for rank correlation did not reject the null of independence between the earlier and later within-region sanitation changes.

\subsection{Parallel Trends Tests}

In this section we evaluate the robustness of our results to alternative hypotheses. We begin by examining whether the sanitation improvements we exploit were correlated with other changes in children's health inputs. Put differently, we investigate whether the parallel trends assumption central to our difference-in-differences strategy holds for the variables that we can observe. The most well-established cause of anemia in children is poor diet and in particular a lack of dietary iron. Deworming medications have also been proved to be important. If sanitation improvements were correlated with improvements in diet, iron intake, and deworming medicines, it would provide evidence against our identification strategy. The DHS allows us to observe data on each of these inputs directly. ${ }^{30}$

\footnotetext{
${ }^{30}$ We examine maternal iron supplementation during pregnancy, for which was data collected in both the 2006 and 2011 rounds of the Nepal DHS. Child iron supplementation is far less common. Data on child iron supplementation was only
} 
To test for parallel trends in observables, in Table 4, we repeat the regression analysis in Table 2, but substitute alternative dependent variables in place of hemoglobin. These include three dietary variables in columns 1 through 6: whether the child ate fruits and vegetables in the last 24 hours; whether the child ate meat and eggs in the last 24 hours; and the variety of diet in the last 24 hours, operationalized as a count of food types (starches, plant protein, fruits and vegetables, meat and eggs, and dairy). Columns 7 through 10 repeat this trends test for an indicator of whether the child took deworming medications in the last six months, and an indicator for whether the mother took iron supplements during pregnancy. ${ }^{31}$

Specifications in Table 4 are similar to those in Table 2. For each of the five dependent variables, hemoglobin would be expected to be increasing in the variable's levels based on the prior literature. The table shows no evidence that improving sanitation was correlated with improvements in diet or increases in iron supplementation or deworming. Across the columns, the correlations with sanitation improvements are not statistically significant. Further, the small point estimates are positive, which if anything would bias against our estimates. Positive point estimates indicate that in places were sanitation was improving more quickly (i.e., greater relative decline in open defecation), diet and deworming were improving less (or declining more). If our effects were due spurious correlations between changes in sanitation and changes in diet, deworming, or iron supplementation, then one would expect negative estimates here, showing that reductions in open defecation were correlated with relative increases in these variables.

Leaving aside the significance of the estimates in Table 4, positive effects of sanitation on food consumption and medicine taking could be consistent with a behavioral response to the biological mechanism we claim to identify. In principle, if parents observed less lethargy and weakness in their children due to improvements in sanitation (and its effects on hemoglobin), they may have endogenously responded to lower rates of open defecation by scaling back intestinal parasite medicine. ${ }^{32}$ Similarly, if children faced less diarrheal disease due to the improving sanitation environment, par-

collected in the 2011 round, in which the mean usage rate was 0.028 - i.e., $2.8 \%$ of sampled children.

${ }^{31}$ The epidemiological literature is not clear on whether mother's in utero iron supplementation continues to have an effect on children's hemoglobin levels by six months of age. Nonetheless, the test is still informative because it can reveal whether our identifying variation is correlated with changes in behavior or beliefs regarding iron supplementation. Further, under the assumption that babies whose mothers took supplements are likely to be born healthier, and therefore less susceptible to disease that could block nutrient absorption or deplete stores, there could be an indirect effect on children's hemoglobin.

${ }^{32}$ It is also possible that parents could reinforce the impacts of OD changes. In that case, estimates would overstate the effects of sanitation improvements, holding all else constant. 
ents may have endogenously responded by reducing the child's food consumption, as a greater fraction of calories consumed would be absorbed and retained in the better disease environment. This could lead to positive coefficient estimates in the table. Our estimation strategy implicitly captures any such general equilibrium effects, in which some of the hemoglobin gains of improved sanitation are counteracted by the compensating reductions in other health inputs. From the perspective of the narrower question of the impacts of sanitation on hemoglobin holding all other behaviors fixed, it would imply our estimates are underestimates.

In summary, the results from the Table 4 analyses suggest that the relationship between open defecation and children's hemoglobin is not merely due to differential trends in "treated" regions along other known determinants of hemoglobin levels. It is important to keep in mind that diet, micronutrient supplementation, malaria, and deworming treatments are the only factors that have been shown to affect of anemia in the prior medical, epidemiological, or economic literature. Since malarial incidence is very low in our country context, the results in Table 4 directly confront this short list of known causal factors, and therefore provide evidence that we have identified a new contributing factor to anemia.

As an additional robustness check, we also replicate the main results in Table 2 with the inclusion of the diet controls. Dietary data were not collected for about a third of our main estimation sample, and adding these controls reduces precision in the hemoglobin-sanitation regressions. Nonetheless, Appendix Table A6 shows that adding dietary controls leaves point estimates essentially unchanged. These new controls include indicators for the child's consumption of meat and eggs in the last 24 hours and fruits and vegetables in the last 24 hours, as well as a control for the number of different kinds of foods in the last 24 hours and indicators for the counts of meals consumed over the last 24 hours. $^{33}$

We next report on a series of tests that evaluate whether improvements in other development indicators (with no obvious theoretical link to anemia) predict changes in hemoglobin over the panel. The aim is to evaluate whether sanitation improvements were merely part of a broader package of local improvements, and whether such broader trends in local development caused hemoglobin

\footnotetext{
${ }^{33}$ The identification strategy of this paper is not designed to estimate the causal effect of the diet and medicine on hemoglobin. Therefore, the coefficients on the food and medicine variables reported in the Table A6 regressions should be interpreted with caution. For example, iron supplementation might be an endogenous response to a pregnant mother learning that she is anemic.
} 
changes or were potentially correlated with an unobservable determinant of hemoglobin. ${ }^{34}$ If withinregion, across-time changes in other markers for local development predicted hemoglobin changes, it would not be an identification problem per se, but it would suggest the need for care in separating the effects of sanitation improvements from other development indicators.

The summary statistics reveal that nationally, household electrification increased by 26 percentage points from 2006 to 2011, and household access to "improved" water sources increased by 9 percentage points. We investigate these infrastructure variables, along with a measure of the social safety net: whether the household has a national health card. The latter measure improved by 4 percentage points (18\%) from 2006 to 2011.

The pattern of the main results in Table 2 already provides some evidence against the notion that sanitation improvements were merely a marker for a wider package of improvements with independent effects on hemoglobin. For example, a comparison of column 5 to column 6 in Table 2 reveals that the inclusion of controls for time varying regional measures of electrification and access to improved water sources had essentially no effect on the estimated effects of $\overline{O D}_{r t}$ and $\overline{O D}_{p r t}$ on hemoglobin. ${ }^{35}$ This indicates that these improvements were either uncorrelated with improvements in open defecation or uncorrelated with changes in children's hemoglobin levels. Appendix Table A7 provides direct evidence in support of the parallel trends assumption, showing that there is no statistically significant association between changes in sanitation and changes in electrification or water access within regions.

In Table 5, we take an alternative approach to examining the possibility of confounding trends by replicating the exact analysis in Table 2, but substituting measures of electrification, water infrastructure, and health card possession in place of open defecation as the regressors of interest. Specifications in Table 5 mirror those in columns 3 and 6 of Table 2, and the corresponding regressions from the main results are repeated in the last two columns for reference. Each regressor is constructed as a bad (e.g., the lack of electricity) so that signs of coefficients are more easily comparable to those for the open defecation variable, which is also a bad. The table shows that with respect to electrification, access to improved water sources, and health card possession, there is no consistent relationship

\footnotetext{
${ }^{34}$ Such a possibility is somewhat mitigated by the fact that the classes of factors influencing anemia in the prior economic, medical, and epidemiological literature is a small set and we have provided evidence on each class of causes in Table 4 . However, there could be an omitted variable unknown in the prior literature.

${ }^{35}$ These variables are included in the time-varying region controls.
} 
between changes in these variables and hemoglobin outcomes. ${ }^{36}$

In all cases, these tests support the identifying assumption that the changes in local open defecation we study were not merely markers for broader local development changes that had independent and confounding effects on our outcome of interest. None of the difference-in-differences results are significant, and moreover, the positive signs of the point estimates in Table 5 are opposite to what would be expected if local trends in these variables were reflecting an omitted factor: a positive sign indicates that where these bads (e.g., lacking electricity) were increasing (or decreasing by less), hemoglobin was differentially improving. This is in contrast to the theoretically-grounded and statistically significant negative effects in the case of open defecation.

\section{Discussion \& Policy Implications}

Today, about $14 \%$ of the world's population practices open defecation. Given the scope of this practice, our estimates imply that poor sanitation could play an important role in explaining variation in anemia rates worldwide. Indeed, our IV estimates—identified within Nepali localities over time-are of the same order of magnitude as the cross-country correlations displayed in Figure $1 .{ }^{37}$

The hypothesis that sanitation has economically important impacts on hemoglobin and anemia is new, but it fits together with several pieces of recent evidence from the economics literature (in addition to the evidence from the epidemiological and medical literature presented in Section 2). Several randomized trials have found an effect of sanitation programs on child height (Cameron, Olivia and Shah, 2013; Gertler et al., 2015; Hammer and Spears, 2016). The biological mechanisms linking open defecation and height are similar to the proposed link between open defecation and hemoglobin status, supporting the plausibility of our findings. Nonetheless, there have been no randomized controlled trials of the effect of latrine or toilet provision on hemoglobin status. Our study is the first to establish this link. ${ }^{38}$ Our findings on anemia may also help to explain some of the recent empirical results in the economics literature. Spears and Lamba (2015) find that exposure to open defecation is associated with lower child cognitive function. Such effects would be consistent

\footnotetext{
${ }^{36}$ The definition of improved water sources follows the definition in the UNICEF/WHO Joint Monitoring Programme for Water Supply and Sanitation and includes piped water, protected wells, and protected springs.

${ }^{37}$ The coefficient estimates implied by Figure 1 range from about $0.10 \mathrm{~g} / \mathrm{dL}$ per 10 percentage point reduction in open defecation (Panel A) to about $0.20 \mathrm{~g} / \mathrm{dL}$ (Panel B). In comparison, the within-region econometric results reported in column 9 of Table 2 imply an effect of $0.196 \mathrm{~g} / \mathrm{dL}$ per 10 percentage point reduction in open defection.

${ }^{38}$ The SHINE trial, currently underway in Zimbabwe, aims to demonstrate the link between the sanitation environment, environmental enteropathy, and anemia. See Humphrey (2014).
} 
on the wider literature about the impacts of anemia on cognition (Stoltzfus et al., 1997).

Our findings have two key implications for researchers and policy makers interested in anemia. First, with respect to research, our study demonstrates the need for future work on anemia and sanitation, but it also suggests that any randomized trial that implements an intervention targeting anemia at the individual level will necessarily miss an important phenomenon. This is because the phenomenon we study is related to the behavior of neighbors: neighbors' open defecation introduces germs and parasites into the child's body. Therefore, changing the open defecation practice of an individual household or deworming individual children (or otherwise arresting the process by which fecal pathogens disrupt the absorption of critical nutrients) are likely to yield very different impacts on hemoglobin than those interventions that randomize at the neighborhood level. This point about the public goods nature of sanitation has been made in the context of deworming interventions by Miguel and Kremer (2004), Bundy et al. (2009), and others. Because open defecation primarily constitutes an externality, research based on individual randomization cannot uncover it.

A related point with respect to policy is that the public goods nature of sanitation also suggests a new set of tools available to address anemia that are fundamentally different from the status quo, which generally involves administering an iron supplement, fortified food, or a deworming pill to an individual child. Our findings imply that policy action can be taken at a community level, and that the reduction of anemia in children may even require action on the part of people who are neither parents nor children. This substantially expands the set of policy responses available for targeting anemia.

Acknowledging that open defecation has external effects on anemia will require a significant shift in thinking for many researchers and policy makers, who tend tend to consider anemia and other nutritional diseases to be problems of inadequate food intake, and to overlook the important role of disease in determining "nutritional" outcomes. Recommendations and interventions aimed at anemia by leading development organizations almost always focus on food-intake based interventions, either in the forms of iron, vitamin B12, and folate supplementation and fortification, or through efforts to encourage people to diversify their diets. However, since exposure to poor sanitation can lead to nutritional loss to intestinal parasites and to the malabsorption of critical nutrients (via enteropathy), sanitation plays a critical role in determining net nutrition.

We do not mean to claim that our findings offer a pathway for a simple solution to the global 
problem of anemia. Changing behavior with respect to open defecation has proven very difficult in many settings. Coffey et al. (2014) catalogues how (stated and revealed) preferences for open defecation can be deeply rooted and not merely a matter of the affordability of toilets. The low private demand for latrines and toilets may be owing to inaccurate beliefs with respect to the private benefits, as well as coordination problems and the classic problem of under-investment in goods with external benefits. Nonetheless, our results offer new evidence of such benefits, and in this way strengthen the basic economic rationale for policy intervention.

\section{Conclusion}

Our study is the first to empirically investigate the hypothesis that poor sanitation is an important contributor to low hemoglobin and anemia in children. The results here suggest new policy avenues for addressing anemia in the developing world, as the elimination of open defecation is rarely among priority policy recommendations or the focus of programs implemented to fight anemia. The finding that open defecation significantly impacts these outcomes adds to a rapidly expanding literature on the importance of open defecation in shaping human capital outcomes. More broadly, our findings connect to a wide literature on the role of water, sanitation, and the disease environment in driving health and human capital accumulation in the developing world and the historical United States. 


\section{References}

Alderman, Harold, and Sebastian Linnemayr. 2009. "Anemia in low-income countries is unlikely to be addressed by economic development without additional programs." Food \& Nutrition Bulletin, 30(3): 265-269.

Allen, Lindsay. 1997. "Pregnancy and iron deficiency: Unresolved issues." Nutrition Reviews, 55(4): 91-101.

Baumgartner, E.A., and Glenn Smith. 1927. "Pernicious anemia and tropical sprue." Archives of Internal Medicine, 40(2): 203-215.

Bertrand, Marianne, Esther Duflo, Sendhil Mullainathan, et al. 2004. "How Much Should We Trust Differences-in-Differences Estimates?" The Quarterly Journal of Economics, 119(1): 249-275.

Bhattacharya, Jayanta, Janet Currie, and Steven Haider. 2004. "Poverty, food insecurity, and nutritional outcomes in children and adults." Journal of Health Economics, 23(4): 839 - 862. Contains contributions from the Grossman Symposium.

Bleakley, Hoyt. 2007. "Disease and development: evidence from hookworm eradication in the American South." The Quarterly Journal of Economics, 122(1): 73-117.

Bobonis, Gustavo J., Edward Miguel, and Charu Puri-Sharma. 2006. "Anemia and School Participation." Journal of Human Resources, XLI(4): 692-721.

Bundy, Donald AP, Michael Kremer, Hoyt Bleakley, Matthew CH Jukes, Edward Miguel, et al. 2009. "Deworming and development: Asking the right questions, asking the questions right." PLoS Neglected Tropical Diseases, 3(1): e362.

Cairncross, Sandy. 2003. "Sanitation in the developing world: Current status and future solutions." International Journal of Environmental Health Research, 13(S1): S123-S131.

Cameron, A Colin, and Douglas L Miller. 2015. "A practitioner's guide to cluster-robust inference." Journal of Human Resources, 50(2): 317-372.

Cameron, A Colin, Jonah B Gelbach, and Douglas L Miller. 2008. "Bootstrap-based improvements for inference with clustered errors." The Review of Economics and Statistics, 90(3): 414-427.

Cameron, Lisa, Susan Olivia, and Manisha Shah. 2013. Impact evaluation of a large-scale rural sanitation project in Indonesia. World Bank.

Clasen, Thomas, Sophie Boisson, Parimita Routray, Belen Torondel, Melissa Bell, Oliver Cumming, Jeroen Ensink, Matthew Freeman, Marion Jenkins, Mitsunori Odagiri, Subhajyoti Ray, Antara Sinha, Mrutyunjay Suar, and Wolf-Peter Schmidt. 2015. "Effectiveness of a rural sanitation programme on diarrhoea, soil-transmitted helminth infection, and child malnutrition in Odisha, India: A cluster-randomised trial." The Lancet Global Health, 2(11): e645-e653.

Coffey, Diane, Aashish Gupta, Payal Hathi, Nidhi Khurana, Dean Spears, Nikhil Srivastav, and Sangita Vyas. 2014. "Revealed preference for open defecation." Economic and Political Weekly, 49(38): 43.

Cohen, Jessica, and Pascaline Dupas. 2010. "Free Distribution or Cost-Sharing? Evidence from a Randomized Malaria Prevention Experiment." The Quarterly Journal of Economics, 125(1): 1-45. 
Cutler, David, and Grant Miller. 2005. "The role of public health improvements in health advances: The twentieth-century United States." Demography, 42(1): 1-22.

Deaton, Angus. 2013. The great escape: Health, wealth, and the origins of inequality. Princeton University Press.

Duh, Josephine, and Dean Spears. 2016. "Health and hunger: disease, energy needs, and the Indian calorie consumption puzzle." The Economic Journal.

Finkelstein, Amy. 2007. “The Aggregate Effects of Health Insurance: Evidence from the Introduction of Medicare." The Quarterly Journal of Economics, 1-37.

Friis, H, D Mwaniki, B Omondi, E Muniu, F Thiong'o, J Ouma, P Magnussen, PW Geissler, and K Fleischer Michaelsen. 2003. "Effects on haemoglobin of multi-micronutrient supplementation and multi-helminth chemotherapy: A randomized, controlled trial in Kenyan school children." European Journal of Clinical Nutrition, 57(4): 573-579.

Gertler, Paul, Manisha Shah, Maria Laura Alzua, Lisa Cameron, Sebastian Martinez, and Sumeet Patil. 2015. "How Does Health Promotion Work? Evidence From The Dirty Business of Eliminating Open Defecation." National Bureau of Economic Research Working Paper 20997.

Geruso, Michael, and Dean Spears. 2015. "Neighborhood Sanitation and Infant Mortality." National Bureau of Economic Research Working Paper 21184.

Government of India. 2011. "Census of India, 2011."

Grantham-McGregor, Sally, and Cornelius Ani. 2001. "Review of Studies on the Effect of Iron Deficiency on Cognitive Development in Children." The Journal of Nutrition, 131: 649S-668S.

Guiteras, Raymond, James Levinsohn, and Ahmed Mushfiq Mobarak. 2015. "Encouraging sanitation investment in the developing world: A cluster-randomized trial." Science, 348(6237): 903-906.

Guiteras, Raymond P, David I Levine, Stephen P Luby, Thomas H Polley, Kaniz Khatun-e Jannat, and Leanne Unicomb. 2014. "Disgust and Shame: Motivating Contributions to Public Goods." mimeo.

Hammer, Jeffrey, and Dean Spears. 2016. "Village sanitation and child health: Effects and external validity in a randomized field experiment in rural India." Journal of Health Economics, 48: 135 - 148.

Hathi, Payal, Sabrina Haque, Lovey Pant, Diane Coffey, and Dean Spears. 2014. "Place and child health: The interaction of population density and sanitation in developing countries." World Bank Policy Research Working Paper, , (7124).

Heston, Alan, Robert Summers, and Bettina Aten. 2012. "Penn World Table Version 7.1."

Humphrey, Jean. 2009. "Child undernutrition, tropical enteropathy, toilets, and handwashing." Lancet, 374: 1032-1035.

Humphrey, Jean. 2014. "Sanitation, Hygiene, Infant Nutrition Efficacy Project." clinicaltrials.gov identifier \# NCT01824940.

Kapoor, SK, Umesh Kapil, Sada Nand Dwivedi, K Anand, Priyali Pathak, and Preeti Singh. 2002. "Comparison of HemoCue method with cyanmethemoglobin method for estimation of hemoglobin." Indian Pediatrics, 39(8): 743-746. 
Knight, Kyle. 2014. "Nepal's 'Mr Toilet' on a clean-up mission." Al Jazeera, April 1, 2014. Available: http://www.aljazeera.com/indepth/features/2014/03/nepal-mr-toilet-clean-up-mission201433195751321643.html [Last accessed: 30 June 2015].

Korenromp, Eline. 2005. "Malaria incidence estimates at country level for the year 2004. Proposed estimates and draft report." World Health Organization, Roll Back Malaria. Geneva: WHO.

Lind, Torbjörn, Bo Lönnerdal, Hans Stenlund, Djauhar Ismail, Rosadi Seswandhana, EvaCharlotte Ekström, and Lars-Åke Persson. 2003. “A community-based randomized controlled trial of iron and zinc supplementation in Indonesian infants: Interactions between iron and zinc." The American Journal of Clinical Nutrition, 77(4): 883-890.

Maluccio, John A, John Hoddinott, Jere R Behrman, Reynaldo Martorell, Agnes R Quisumbing, and Aryeh D Stein. 2009. "The impact of improving nutrition during early childhood on education among Guatemalan adults." The Economic Journal, 119(537): 734-763.

Measure DHS. 2013. "Malaria Indicator Survey: Anemia and Malaria Field TestingManual." Measure DHS, Calverton, MD. Available: www. malariasurveys. org/toolkit.

Menon, Purnima. 2012. "The crisis of poor complementary feeding in South Asia: Where next?" Maternal \& Child Nutrition, 8(s1): 1-4.

Miguel, Edward, and Michael Kremer. 2004. "Worms: Identifying Impacts on Education and Health in the Presence of Treatment Externalities." Econometrica, 72(1): 159-217.

Nath, Samir. 2005. “Tropical Sprue." Current Gastroenterology Reports, 7: 343-349.

Ozier, Owen. 2015. "Exploiting Externalities to Estimate the Long-Term Effects of Early Childhood Deworming." Development Research Group, The World Bank.

Rosenberg, Irwin, and Barbara Bowman. 1982. "Intestinal Physiology and Parasitic Diseases." Reviews of Infectious Diseases, 4(4): 763-767.

Rush, David. 2000. "Nutrition and maternal mortality in the developing world." American Journal of Clinical Nutrition, 72(suppl): 212S-240S.

Sachs, Jeffrey, and Pia Malaney. 2002. "The economic and social burden of malaria." Nature, 415(6872): 680-685.

Spears, Dean. 2012. "Effects of Rural Sanitation on Infant Mortality and Human Capital: Evidence from a Local Governance Incentive in India." Princeton working paper.

Spears, Dean. 2013. "How Much International Variation in Child Height Can Sanitation Explain?" The World Bank.

Spears, Dean, and Sneha Lamba. 2015. "Effects of early-life exposure to sanitation on childhood cognitive skills: Evidence from India?s Total Sanitation Campaign." Journal of Human Resources.

Spears, Dean, Arabinda Ghosh, and Oliver Cumming. 2013. "Open defecation and childhood stunting in India: an ecological analysis of new data from 112 districts." PLoS One, 8(9): e73784.

Stevens, Gretchen A, Mariel M Finucane, Luz Maria De-Regil, Christopher J Paciorek, Seth R Flaxman, Francesco Branca, Juan Pablo Peña-Rosas, Zulfiqar A Bhutta, Majid Ezzati, Nutrition Impact Model Study Group, et al. 2013. "Global, regional, and national trends in haemoglobin concentration and prevalence of total and severe anaemia in children and pregnant and non-pregnant 
women for 1995-2011: A systematic analysis of population-representative data." The Lancet Global Health, 1(1): e16-e25.

Stoltzfus, Rebecca J, Hababu M Chwaya, James M Tielsch, Kerry J Schulze, Marco Albonico, and Lorenzo Savioli. 1997. "Epidemiology of iron deficiency anemia in Zanzibari schoolchildren: The importance of hookworms." The American Journal of Clinical Nutrition, 65(1): 153-159.

Tayler, Kevin, Rebecca Scott, and Guna Raj Shrestha. 2005. "Implementing National Sanitation Policy in Nepal." WEDC Briefing Note: Nepal.

Taylor-Robinson, David C, Nicola Maayan, Karla Soares-Weiser, Sarah Donegan, and Paul Garner. 2012. "Deworming drugs for soil-transmitted intestinal worms in children: Effects on nutritional indicators, haemoglobin and school performance." Cochrane Database Syst Rev, 7.

Thomas, Duncan, Elizabeth Frankenberg, Jed Friedman, Jean-Pierre Habicht, Nathan Jones, Christopher McKelvey, Greta Pelto, Bondan Sikoki, James Smith, Cecep Sumantri, and Wayan Suriastini. 2004. "Causal Effect of Health on Labor Market Outcomes: Evidence from a Random Assignment Iron Supplementation Intervention." California Center for Population Research Working Paper.

Tolentino, Karine, and Jennifer Friedman. 2007. "An update on anemia in less developed countries." The American Journal of Tropical Medicine and Hygiene, 77(1): 44-51.

Van Stuijvenberg, M Elizabeth, Jane D Kvalsvig, Mieke Faber, Marita Kruger, Diane G Kenoyer, and AJ Spinnler Benadé. 1999. "Effect of iron-, iodine-, and $\beta$-carotene-fortified biscuits on the micronutrient status of primary school children: A randomized controlled trial." The American Journal of Clinical Nutrition, 69(3): 497-503.

Walker, Marjorie. 2003. "What is tropical sprue?" Journal of Gastroenterology and Hepatology, 18(8): 887-890.

Watson, Tara. 2006. "Public health investments and the infant mortality gap: Evidence from federal sanitation interventions on U.S. Indian reservations." Journal of Public Economics, 90(8-9): 1537 1560 .

World Bank. 2013. “Data: Land area (sq. km).”

Yip, Ray, and Usha Ramakrishnan. 2002. "Experiences and challenges in developing countries." The Journal of Nutrition, 132(4): 827S-830S. 
Figure 1: Motivating Facts: Cross-Country Relationships between Hemoglobin \& Open Defecation

(A) Unconditional Correlation

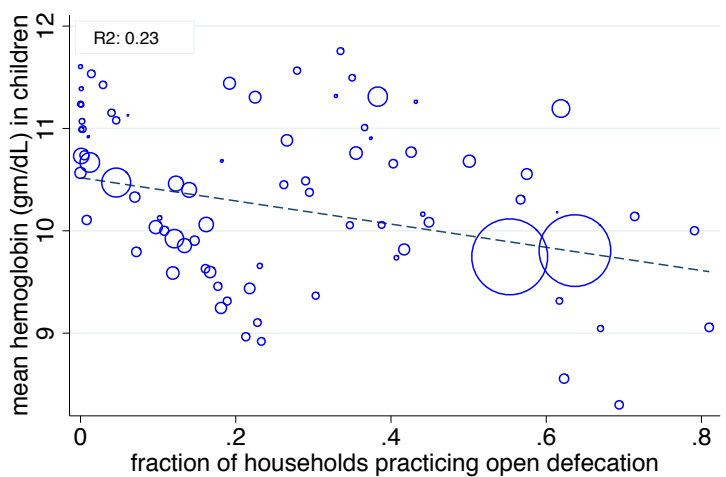

(C) Controlling for Income and Malaria

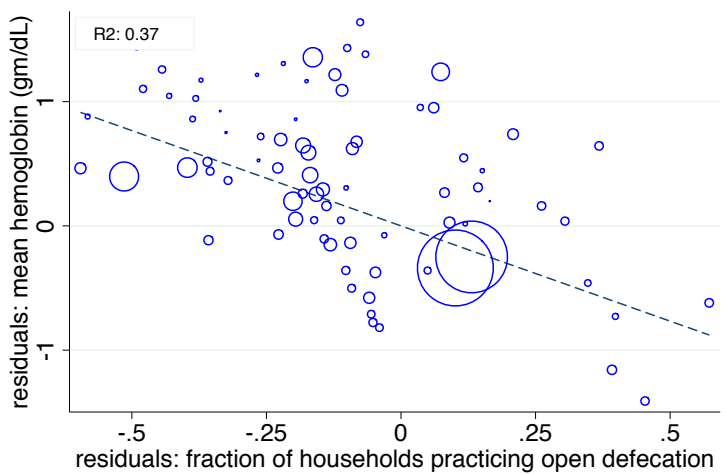

(E) Controlling for Diet, Income, Malaria

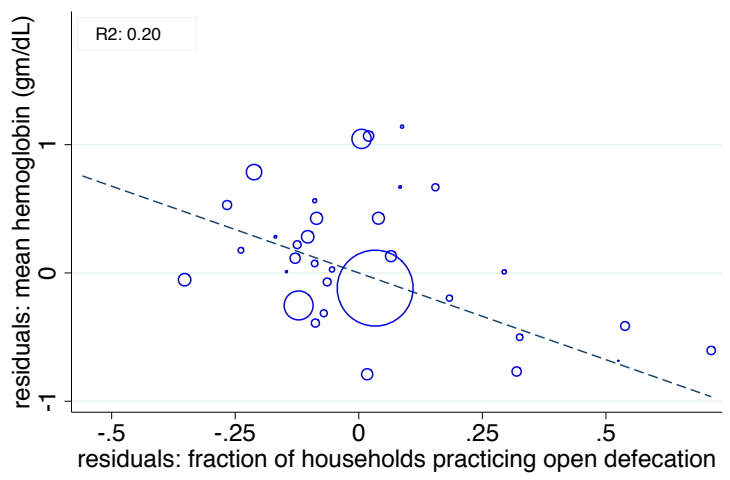

(B) Unconditional Correlation

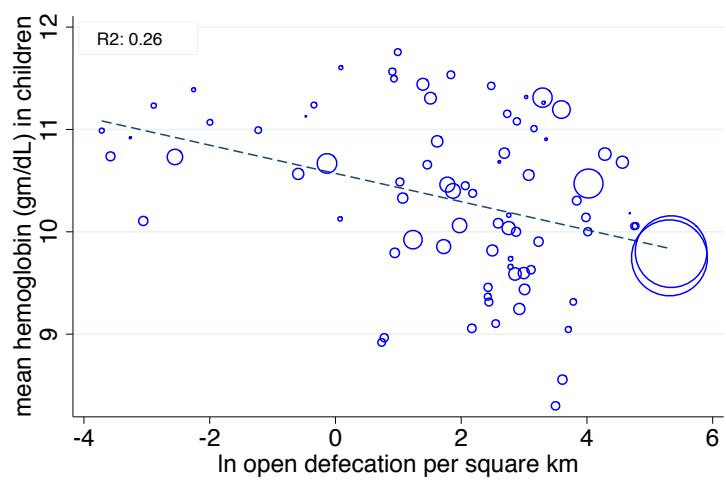

(D) Controlling for Income and Malaria

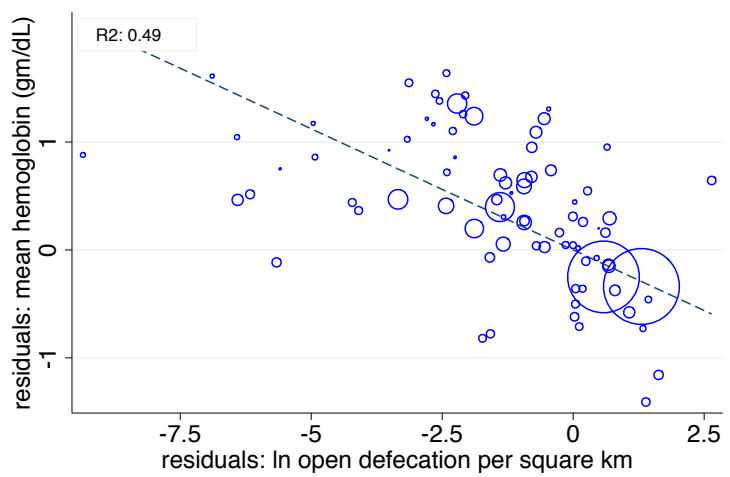

(F) Controlling for Diet, Income, Malaria

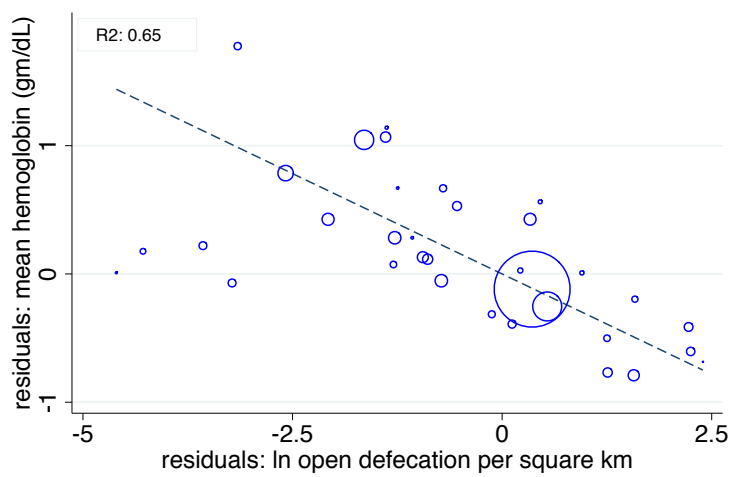

Note: Figure shows the cross-country relationship between fraction of households practicing open defecation and hemoglobin levels in children aged 6 to 35 months. Each point in the scatterplots corresponds to a country $\times$ year mean of a Demographic and Health Survey. Marker sizes are proportional to country populations. Panels A through D contain 81 DHS surveys. Panels E and F contain the subset of 35 DHS surveys for which dietary information was available. See Appendix Table A1 for a list of the DHS surveys represented in the plots. Dashed lines in each plot correspond to regression coefficients from population-weighted regressions. 
Figure 2: Identifying Variation: Within-Region Sanitation Improvements, 2006 to 2011

(A) Rural Areas of 13 Regions of Nepal

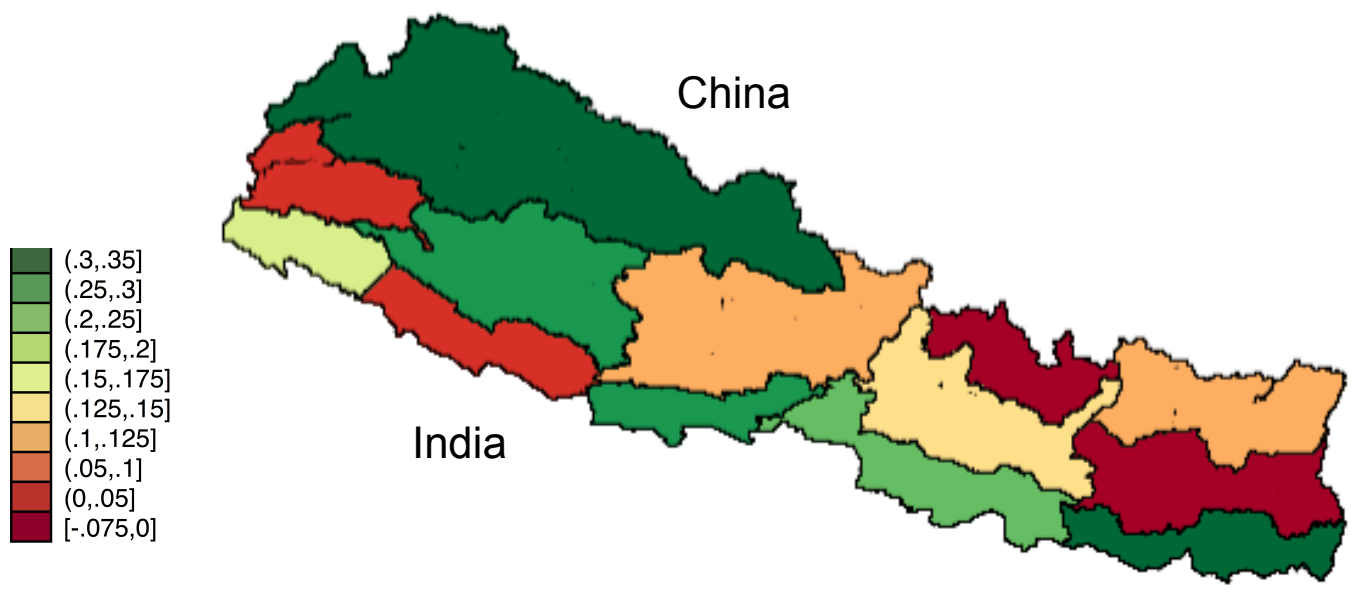

(B) Urban Areas of 12 Regions of Nepal

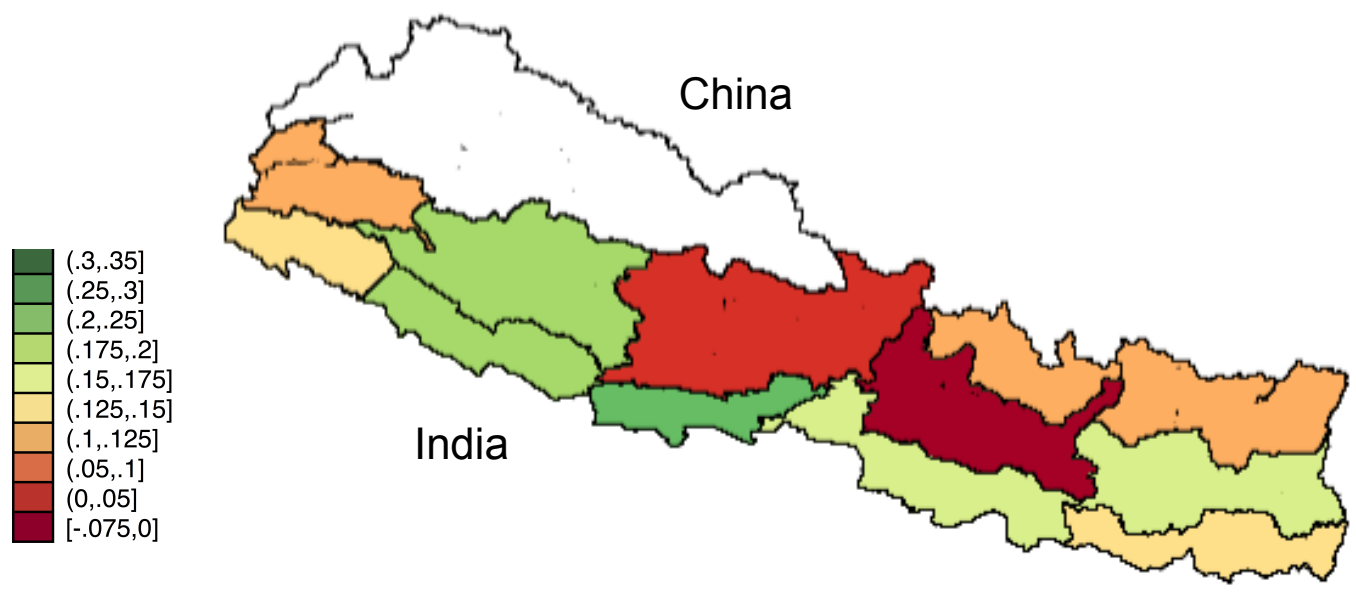

Note: Figure shows improvements in sanitation between the 2006 and 2011 rounds of the Nepal DHS. Regions are color-coded according to the change in fraction of households using toilets and latrines (equal to one minus the fraction of households defecating in the open). Darker greens indicate greater improvements in sanitation. Darker reds indicate lesser improvements. Panel A includes only rural households within each of 13 regions. Panel B includes only urban households of 12 regions. In Panel B, the Western Mountain Region (upper left) contained no urban areas. 
Figure 3: Baseline Sanitation in 2006 Predicts Subsequent Improvement

(A) Rural Areas of 13 Regions

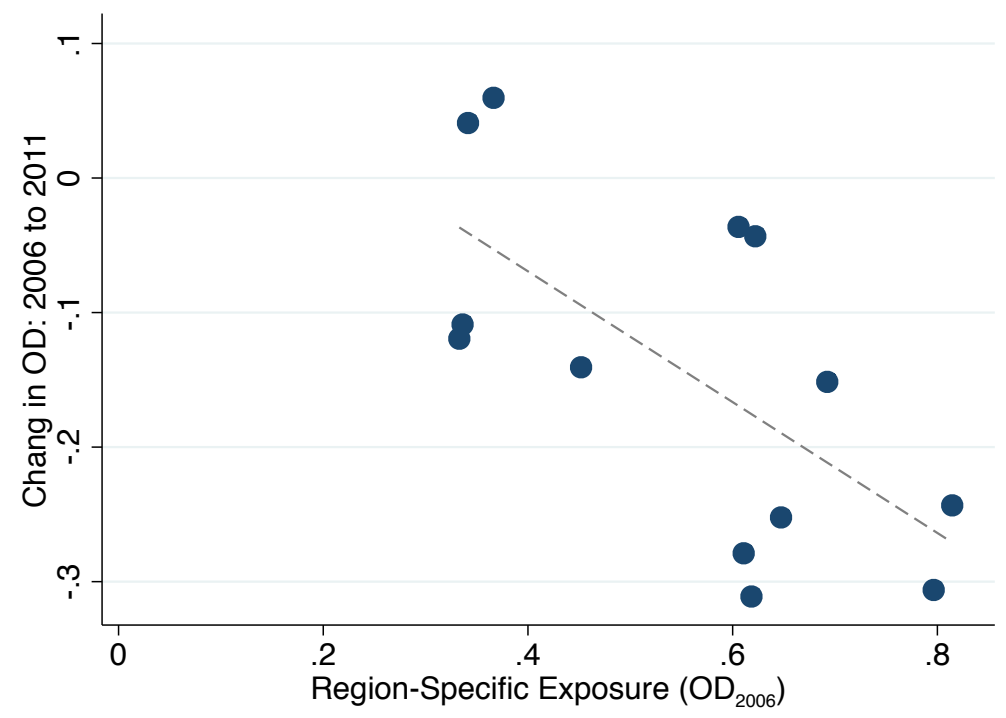

(B) Urban Areas of 12 Regions

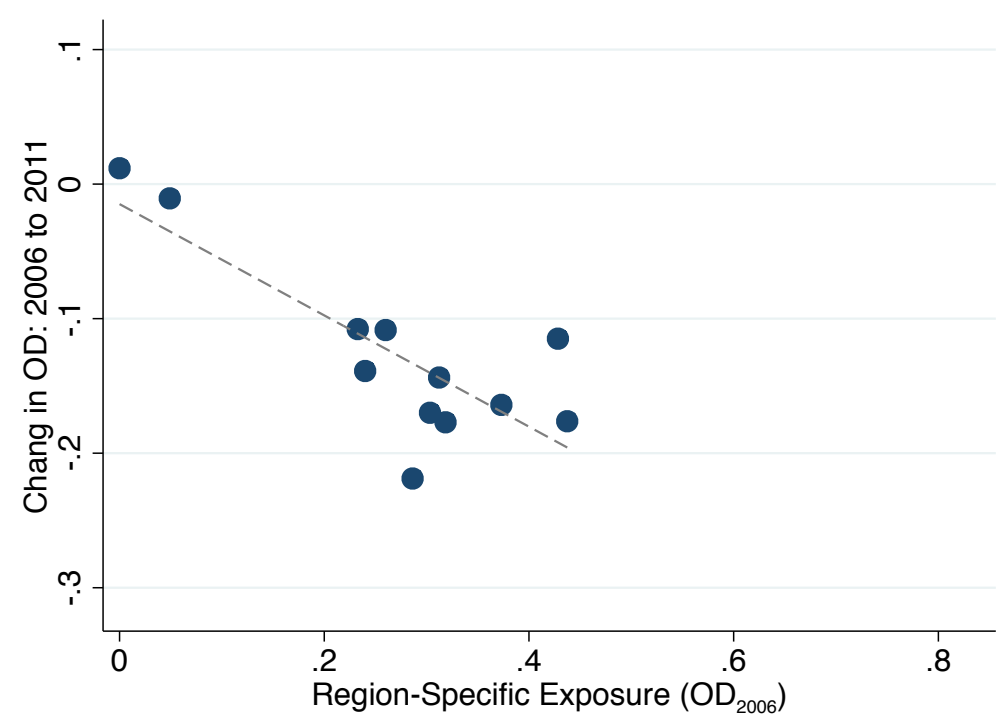

Note: Figure plots the relationship between a region's Exposure to national sanitation improvements and the subsequent within-region change in open defecation (OD) between 2006 and 2011. Exposure is defined as the baseline level of open defecation in 2006. Panel A includes only rural households within each of 13 regions. Panel B includes only urban households. The number of regions in panel B is smaller because the Western Mountain Region of Nepal contained no urban areas. Regressions estimating the slopes are presented in Table A3. Slopes are significant at $p<.01$. 
Table 1: Summary Statistics

\begin{tabular}{|c|c|c|c|c|c|c|c|c|}
\hline & \multicolumn{4}{|c|}{ Full Sample } & \multicolumn{4}{|c|}{ Food Subsample } \\
\hline & \multicolumn{2}{|c|}{2006 Round } & \multicolumn{2}{|c|}{2011 Round } & \multicolumn{2}{|c|}{2006 Round } & \multicolumn{2}{|c|}{2011 Round } \\
\hline & Mean & SD & Mean & SD & Mean & SD & Mean & SD \\
\hline & $(1)$ & $(2)$ & $(3)$ & (4) & $(5)$ & (6) & $(7)$ & $(8)$ \\
\hline child hemoglobin (g/dL) & 11.16 & 1.44 & 11.21 & 1.41 & 10.99 & 1.45 & 10.86 & 1.38 \\
\hline child anemia, mild $(<11 \mathrm{~g} / \mathrm{dL})$ & 0.42 & 0.49 & 0.41 & 0.49 & 0.47 & 0.50 & 0.51 & 0.50 \\
\hline child anemia, moderate $(<10 \mathrm{~g} / \mathrm{dL})$ & 0.19 & 0.39 & 0.17 & 0.38 & 0.23 & 0.42 & 0.24 & 0.43 \\
\hline child anemia, severe $(<7 \mathrm{~g} / \mathrm{dL})$ & 0.01 & 0.07 & 0.00 & 0.07 & 0.01 & 0.09 & 0.01 & 0.09 \\
\hline child age in months & 33.10 & 15.44 & 32.94 & 15.35 & 28.54 & 14.67 & 24.56 & 15.24 \\
\hline child male & 0.50 & 0.50 & 0.52 & 0.50 & 0.48 & 0.50 & 0.47 & 0.50 \\
\hline household open defecation & 0.59 & 0.49 & 0.46 & 0.50 & 0.61 & 0.49 & 0.50 & 0.50 \\
\hline household sanitation ( 1 - open defecation) & 0.41 & 0.49 & 0.54 & 0.50 & 0.39 & 0.49 & 0.50 & 0.50 \\
\hline household electricity & 0.40 & 0.49 & 0.66 & 0.47 & 0.37 & 0.48 & 0.61 & 0.49 \\
\hline household improved water source & 0.78 & 0.41 & 0.87 & 0.34 & 0.77 & 0.42 & 0.85 & 0.35 \\
\hline household has health card & 0.22 & 0.42 & 0.26 & 0.44 & 0.26 & 0.44 & 0.34 & 0.47 \\
\hline household urban & 0.21 & 0.41 & 0.20 & 0.40 & 0.20 & 0.40 & 0.18 & 0.38 \\
\hline mother some education & 0.38 & 0.48 & 0.52 & 0.50 & 0.37 & 0.48 & 0.52 & 0.50 \\
\hline mother literate & 0.46 & 0.50 & 0.59 & 0.49 & 0.45 & 0.50 & 0.58 & 0.49 \\
\hline child took parasite medication, last 6 months & 0.75 & 0.43 & 0.77 & 0.42 & 0.71 & 0.46 & 0.66 & 0.47 \\
\hline mother took iron supplements during pregnancy ${ }^{a}$ & 0.53 & 0.50 & 0.78 & 0.42 & 0.56 & 0.50 & 0.82 & 0.38 \\
\hline child ate fruits and vegetables, last $24 \mathrm{hrs}$ & & & & & 0.60 & 0.49 & 0.40 & 0.49 \\
\hline child ate meat and eggs, last $24 \mathrm{hrs}$ & & & & & 0.21 & 0.41 & 0.23 & 0.42 \\
\hline count of kinds of food child ate, last $24 \mathrm{hrs}$ & & & & & 2.29 & 1.23 & 1.97 & 1.25 \\
\hline observations & \multicolumn{2}{|c|}{4,469} & \multicolumn{2}{|c|}{1,995} & \multicolumn{2}{|c|}{3,371} & \multicolumn{2}{|c|}{997} \\
\hline
\end{tabular}

Note: Table displays summary statistics for the 2006 and 2011 rounds of the Nepal Demographic and Health Survey (DHS). Statistics are calculated separately for our main analysis sample ("full sample") and for the subsample in which dietary information was collected ("food subsample"). Observations are children aged 6 to 59 months. The sample sizes are smaller in 2011 than 2006 by survey design. In 2006, the DHS collected hemoglobin data from all children aged 6 to 59 months, but in 2011 collected hemoglobin data for a random 50\% subsample in this age range. anformation on mother's use of iron supplementation during pregnancy was only recorded with respect to the most recent pregnancy for each mother. See Appendix Table A2 for an additional set of summary statistics calculated over the subsample for which the iron supplementation question was asked. 
Table 2: Main Results: Effects of Open Defecation (OD) on Children's Hemoglobin

\begin{tabular}{|c|c|c|c|c|c|c|}
\hline \multirow{4}{*}{$\begin{array}{l}\text { Dependent variable: } \\
\text { Specification: } \\
\text { Sample: }\end{array}$} & \multicolumn{6}{|c|}{ Hemoglobin $(\mathrm{g} / \mathrm{dL})$} \\
\hline & \multicolumn{3}{|c|}{ Pooled Cross-Section } & \multicolumn{3}{|c|}{ D-in-D } \\
\hline & Full & Full & Full & Full & Full & Full \\
\hline & $(1)$ & $(2)$ & $(3)$ & $(4)$ & $(5)$ & $(6)$ \\
\hline Region mean OD & $\begin{array}{c}-0.91^{* *} \\
(0.17)\end{array}$ & $\begin{array}{c}-0.59 * * \\
(0.18)\end{array}$ & $\begin{array}{c}-0.90^{* *} \\
(0.25)\end{array}$ & $\begin{array}{c}-1.53^{* *} \\
(0.49)\end{array}$ & $\begin{array}{c}-1.19^{*} \\
(0.48)\end{array}$ & $\begin{array}{c}-1.27^{*} \\
(0.50)\end{array}$ \\
\hline Survey round FEs & $\mathrm{x}$ & $\mathrm{x}$ & $\mathrm{x}$ & $\mathrm{x}$ & $\mathrm{x}$ & $\mathrm{x}$ \\
\hline Age-in-month $X$ sex indicators & $x$ & $x$ & $x$ & $x$ & $\mathrm{x}$ & $x$ \\
\hline Own OD & & $\mathrm{x}$ & $\mathrm{x}$ & & $\mathrm{x}$ & $\mathrm{x}$ \\
\hline Economic controls & & & $\mathrm{X}$ & & & $\mathrm{x}$ \\
\hline Mother education controls & & & $\mathrm{x}$ & & & $\mathrm{x}$ \\
\hline Parasite medicine & & & $x$ & & & $x$ \\
\hline Time-varying region controls & & & $\mathrm{x}$ & & & $\mathrm{x}$ \\
\hline Region FEs & & & & $x$ & $\mathrm{x}$ & $x$ \\
\hline Mean of dependent variable & 11.2 & 11.2 & 11.2 & 11.2 & 11.2 & 11.2 \\
\hline Observations & 6,464 & 6,464 & 6,464 & 6,464 & 6,464 & 6,464 \\
\hline
\end{tabular}

Note: Table reports results from a series of OLS regressions. The dependent variable in all columns is the child's hemoglobin level. All columns control for survey round fixed effects, religion indicators, and a complete set of agein-month $\times$ sex indicators. Columns 4 through 6 include region fixed effects. Economic controls include indicators for 5 household assets asked about in both survey rounds, an indicator for household electricity, and indicators for type of wall materials (9 categories), roof materials (8 categories), and floor materials (6 categories) that makeup the child's dwelling. Parasite medicine is an indicator for the consumption of intestinal parasite medication in the last six months. Mother's education controls include an indicator for literacy and indicators for levels of educational attainment (4 categories). Region controls add continuous measures of electrification and the use of improved water sources at the regional level. Observations are children. Standard errors are clustered at the PSU level. $+p<0.1, *$ $p<0.05,{ }^{* *} p<0.01$. 
Table 3: Robustness: Instrumenting within-Region Sanitation Changes with 2006 Exposure

\begin{tabular}{|c|c|c|c|c|}
\hline \multirow{3}{*}{$\begin{array}{l}\text { Dependent variable: } \\
\text { Specification: }\end{array}$} & \multicolumn{4}{|c|}{ Change in Mean Hemoglobin ( $\mathrm{g} / \mathrm{dL}$ ) within Region } \\
\hline & OLS & OLS & IV & IV \\
\hline & $(1)$ & $(2)$ & (3) & (4) \\
\hline \multirow[t]{2}{*}{ Change in mean OD within region } & $-1.53^{*}$ & $-1.72 * *$ & $-2.86^{*}$ & $-2.88 * *$ \\
\hline & $(0.55)$ & $(0.54)$ & $(1.44)$ & $(0.71)$ \\
\hline Urban & & $X$ & & $\mathrm{X}$ \\
\hline Change in mean electrification within region & & $x$ & & $\mathrm{X}$ \\
\hline Change in mean improved water source within region & & $x$ & & $\mathrm{X}$ \\
\hline Mean of dependent variable & -0.10 & -0.10 & -0.10 & -0.10 \\
\hline First stage F-stat & & & 16.3 & 25.3 \\
\hline Observations (regions) & 25 & 25 & 25 & 25 \\
\hline
\end{tabular}

Note: Table reports results from a series of OLS and IV regressions in which the unit of analysis is the region. The dependent variable in all columns is the change in regional mean of children's hemoglobin levels between 2006 and 2011. IV regressions in columns 3 and 4 instrument for the change in mean open defecation within the region $\left(\Delta \overline{O D}_{r}\right)$ with an exposure variable, defined as the 2006 level $\left(\overline{O D}_{r, 2006}\right)$. First stage regressions corresponding to columns 3 and 4 are displayed in Table A3. Observations are the 25 regions, defined by 13 geographic areas interacted with an urban indicator. Robust standard errors are reported. $+p<0.1,{ }^{*} p<0.05,{ }^{* *} p<0.01$. 
Table 4: Parallel Trends Assumption: Sanitation Improvements Uncorrelated with Changes to Diet and Medicine-Taking

\begin{tabular}{|c|c|c|c|c|c|c|c|c|c|c|}
\hline \multirow{4}{*}{$\begin{array}{l}\text { Dependent variable: } \\
\text { Specification: } \\
\text { Sample: }\end{array}$} & \multicolumn{2}{|c|}{$\begin{array}{l}\text { Child Ate Meat } \\
\text { and Eggs, } \\
\text { Last } 24 \text { Hours }\end{array}$} & \multicolumn{2}{|c|}{$\begin{array}{c}\text { Child Ate Fruits and } \\
\text { Vegetables, } \\
\text { Last } 24 \text { Hours } \\
\end{array}$} & \multicolumn{2}{|c|}{$\begin{array}{c}\text { Dietary Diversity: } \\
\text { Diff. Kinds of Food, } \\
\text { Last } 24 \text { Hours }\end{array}$} & \multicolumn{2}{|c|}{$\begin{array}{l}\text { Child Intestinal } \\
\text { Parasite Medicine } \\
\text { (Deworming) }\end{array}$} & \multicolumn{2}{|c|}{$\begin{array}{c}\text { Mother Iron } \\
\text { Supplements During } \\
\text { Pregnancy }\end{array}$} \\
\hline & Cross-Sec. & D-in-D & Cross-Sec. & D-in-D & Cross-Sec. & D-in-D & Cross-Sec. & D-in-D & Cross-Sec. & D-in-D \\
\hline & Food & Food & Food & Food & Food & Food & Full & Full & Iron & Iron \\
\hline & $(1)$ & $(2)$ & $(3)$ & $(4)$ & $(5)$ & $(6)$ & $(7)$ & $(8)$ & (9) & (10) \\
\hline Region mean OD & $\begin{array}{l}-0.07 \\
(0.09)\end{array}$ & $\begin{array}{c}0.14 \\
(0.20)\end{array}$ & $\begin{array}{l}-0.08 \\
(0.10)\end{array}$ & $\begin{array}{c}0.11 \\
(0.21)\end{array}$ & $\begin{array}{c}-0.36+ \\
(0.21)\end{array}$ & $\begin{array}{c}0.55 \\
(0.46)\end{array}$ & $\begin{array}{c}0.10 \\
(0.06)\end{array}$ & $\begin{array}{l}0.21+ \\
(0.13)\end{array}$ & $\begin{array}{c}0.02 \\
(0.09)\end{array}$ & $\begin{array}{l}-0.15 \\
(0.17)\end{array}$ \\
\hline Survey round FEs & $x$ & $x$ & $x$ & $x$ & $x$ & $x$ & $\mathrm{x}$ & $x$ & $\mathrm{X}$ & $X$ \\
\hline Age-in-month $X$ sex indicators & $x$ & $x$ & $x$ & $x$ & $x$ & $x$ & $x$ & $x$ & $x$ & $x$ \\
\hline Own OD & $x$ & $x$ & $x$ & $x$ & $x$ & $x$ & $x$ & $x$ & $x$ & $x$ \\
\hline Economic controls & $x$ & $x$ & $x$ & $x$ & $x$ & $x$ & $x$ & $x$ & $x$ & $x$ \\
\hline Mother education controls & $x$ & $x$ & $x$ & $x$ & $x$ & $x$ & $x$ & $x$ & $x$ & $x$ \\
\hline Parasite medicine & $x$ & $x$ & $x$ & $x$ & $x$ & $x$ & & & $x$ & $x$ \\
\hline Time-varying region controls & $x$ & $x$ & $x$ & $x$ & $x$ & $x$ & $x$ & $x$ & $x$ & $x$ \\
\hline Region FEs & & $x$ & & $x$ & & $x$ & & $x$ & & $\mathrm{x}$ \\
\hline Mean of dependent variable & 0.21 & 0.21 & 0.56 & 0.56 & 2.22 & 2.22 & 0.76 & 0.76 & 0.61 & 0.61 \\
\hline Observations & 4,348 & 4,348 & 4,348 & 4,348 & 4,348 & 4,348 & 6,464 & 6,464 & 4,720 & 4,720 \\
\hline
\end{tabular}

Note: Table reports results from a series of OLS regressions that test the parallel trends assumption. The dependent variables in the table differ across columns. Each dependent variable represents an outcome or behavior which is likely to directly affect hemoglobin levels. These dependent variables include an indicator for whether the child has eaten meat or eggs in the last 24 hours, an indicator whether the child has eaten fruits or vegetables in the last 24 hours, a continuous variable for the count of kinds of different foods the child has eaten within the last 24 hours, an indicator for whether the child has taken intestinal parasite medication within the last six months, and an indicator for whether the mother took iron supplements during pregnancy. Controls are as described in the Table 2 notes. Observations are children. Sample sizes vary because survey information on diet was collected for only a subsample of children in each household $(\mathrm{N}=4,348)$ and because survey information about maternal iron supplementation was only collected for each mother's most recent pregnancy $(\mathrm{N}=4,720)$. See Table A2 and text for full details. Standard errors are clustered at the PSU level. $+p<0.1,{ }^{*} p<0.05,{ }^{* *}$ $p<0.01$. 


\section{Table 5: Other Regional Improvements Do Not Predict Hemoglobin Changes}

\begin{tabular}{|c|c|c|c|c|c|c|c|c|}
\hline \multirow{3}{*}{$\begin{array}{l}\text { Dependent variable: } \\
\text { Regressor of Interest: } \\
\text { Specification: }\end{array}$} & \multicolumn{8}{|c|}{ Hemoglobin $(\mathrm{g} / \mathrm{dL})$} \\
\hline & \multicolumn{2}{|c|}{ No Electricity } & \multicolumn{2}{|c|}{$\begin{array}{c}\text { No Improved Water } \\
\text { Source }\end{array}$} & \multicolumn{2}{|c|}{ No Health Card } & \multicolumn{2}{|c|}{$\begin{array}{l}\text { OD Effects } \\
\text { (repeated for } \\
\text { reference) }\end{array}$} \\
\hline & Cross-Sec. & D-in-D & Cross-Sec. & D-in-D & Cross-Sec. & D-in-D & Cross-Sec. & D-in-D \\
\hline & $\begin{array}{c}\text { Full } \\
(1)\end{array}$ & $\begin{array}{c}\text { Full } \\
(2)\end{array}$ & $\begin{array}{c}\text { Full } \\
(3)\end{array}$ & $\begin{array}{c}\text { Full } \\
(4)\end{array}$ & $\begin{array}{c}\text { Full } \\
(5)\end{array}$ & $\begin{array}{c}\text { Full } \\
(6)\end{array}$ & $\begin{array}{c}\text { Full } \\
(7)\end{array}$ & $\begin{array}{l}\text { Full } \\
(8)\end{array}$ \\
\hline Region mean (lacking electrification) & $\begin{array}{l}0.28+ \\
(0.15)\end{array}$ & $\begin{array}{c}0.21 \\
(0.31)\end{array}$ & & & & & & \\
\hline Region mean (unimproved water source) & & & $\begin{array}{l}1.56 * * \\
(0.25)\end{array}$ & $\begin{array}{c}0.54 \\
(0.39)\end{array}$ & & & & \\
\hline Region mean (family lacks healthcare card) & & & & & $\begin{array}{c}0.21 \\
(0.31)\end{array}$ & $\begin{array}{c}0.19 \\
(0.72)\end{array}$ & & \\
\hline Region mean (open defecation) & & & & & & & $\begin{array}{c}-0.90^{* *} \\
(0.25)\end{array}$ & $\begin{array}{r}-1.27^{*} \\
(0.50)\end{array}$ \\
\hline Survey round FEs & $\mathrm{x}$ & $\mathrm{x}$ & $\mathrm{x}$ & $\mathrm{x}$ & $\mathrm{x}$ & $\mathrm{x}$ & $\mathrm{x}$ & $\mathrm{x}$ \\
\hline Age-in-month $\mathrm{X}$ sex indicators & $x$ & $\mathrm{x}$ & $x$ & $\mathrm{x}$ & $\mathrm{x}$ & $\mathrm{x}$ & $\mathrm{x}$ & $\mathrm{x}$ \\
\hline Own [electrification/water/card] & $x$ & $x$ & $x$ & $\mathrm{x}$ & $x$ & $x$ & $x$ & $x$ \\
\hline Economic controls & $\mathrm{x}$ & $\mathrm{x}$ & $\mathrm{x}$ & $\mathrm{x}$ & $\mathrm{x}$ & $\mathrm{x}$ & $\mathrm{x}$ & $\mathrm{x}$ \\
\hline Mother education controls & $x$ & $x$ & $x$ & $x$ & $x$ & $\mathrm{x}$ & $x$ & $x$ \\
\hline Parasite medicine & $\mathrm{x}$ & $\mathrm{x}$ & $\mathrm{x}$ & $\mathrm{x}$ & $\mathrm{x}$ & $x$ & $\mathrm{x}$ & $\mathrm{x}$ \\
\hline Time-varying region controls & & & & & & & $x$ & $x$ \\
\hline Region FEs & & $x$ & & $\mathrm{x}$ & & $\mathrm{x}$ & & $x$ \\
\hline Mean of dependent variable & 11.2 & 11.2 & 11.2 & 11.2 & 11.2 & 11.2 & 11.2 & 11.2 \\
\hline Observations & 6,464 & 6,464 & 6,464 & 6,464 & 6,464 & 6,464 & 6,464 & 6,464 \\
\hline
\end{tabular}

Note: Table reports results from a series of OLS regressions. The dependent variable in all columns is the child's hemoglobin level. The regressor of interest varies across columns. In columns 1 and 2, the regressor of interest is the regional mean of an indicator for households lacking electricity. In columns 3 and 4, it is the regional mean of an indicator for households lacking access to "improved" water sources, which include piped water, protected wells, and protected springs. In columns 5 and 6, the regressor of interest is the regional mean of an indicator for households lacking a national health card. Controls are as described in the Table 2 notes. Observations are children. Standard errors are clustered at the PSU level. $+p<0.1,{ }^{*} p<0.05,{ }^{* *} p<0.01$. 


\section{APPENDIX}

\section{A.1 Data Used in Section 2}

For the motivating analysis in Section 2, data come from several sources. Anemia and open defecation data used to construct Figure 1 come from the Demographic and Health Surveys of 45 countries and 18 survey years, spanning 1995-2012. A complete listing of the country-years is provided in Table A1. Each of the country-years was matched with time invariant data from the World Bank on land area (World Bank, 2013) and with time variant data from the Penn World Tables on population (Heston, Summers and Aten, 2012). These data were used to construct an estimate of the number of people who defecate in the open per square kilometer. The estimate of open defecation per square kilometer is derived by multiplying the fraction of households that defecate in the open by the population of the country in the year of interest, dividing by the land area in kilometers, and taking the log. ${ }^{39}$ The control for GDP per capita is time variant and is also taken from the Penn World Tables. GDP per capita is in US dollars, converted using the Laspeyere's PPP conversion (Heston, Summers and Aten, 2012).

The control for malaria exposure is a time invariant estimate of malaria incidence in children under five generated by Korenromp (2005) for the WHO. For Africa, these estimates were generated based on 22 longitudinal studies from populations with no access to malaria prevention. The studies defined malaria as fever with malaria parasitemia on a blood slide. In some countries in southern Africa, national malaria case notification rates were used. Korenromp (2005) points out that for countries outside of Africa, there were fewer longitudinal studies on which to base the malaria estimates.

\section{A.2 Complementary IV Approach to D-in-D Results of Table 2}

Including neighborhood fixed effects in Table 2 is not possible because the DHS sampling scheme did not re-interview in the same neighborhoods in the 2006 and 2011 rounds. Therefore, in order to narrow the geographic unit of the sanitation environment to the neighborhood while still exploiting only the within-region, over-time variation on display in Figure 2, we additionally present results from a complementary IV strategy. We instrument for PSU-level sanitation $\left(\overline{O D}_{p r t}^{P S U}\right)$ with region $\times$ survey round variation:

$$
\begin{aligned}
& H b_{i p r t}=\beta_{1} \widehat{\overline{O D}}_{p r t}^{P S U}+\alpha_{2011}+\sum_{r \in R} \alpha_{r} r+f\left(X_{i p r t}\right)+\epsilon_{i p r t} \\
& \widehat{\widehat{O D}}_{p r t}^{P S U}=\lambda_{1} \overline{O D}_{r t}+\gamma_{2011}+\sum_{r \in R} \gamma_{r} r+g\left(X_{i p r t}\right)+\mu_{i p r t} .
\end{aligned}
$$

Here, the redundant superscript PSU is included to emphasize that open defecation means are taken at the PSU level (co-located clusters of approximately 100-200 households). Projecting PSU-level sanitation, $\overline{O D}_{p r t}^{P S U}$, onto region-level sanitation, $\overline{O D}_{r t}$, avoids identifying estimates partially off of cross-sectional differences across PSUs within a region $\times$ year. Intuitively, while the IV projection in Eq. 5 controls for any PSU-level variation within a region-year, it still allows the sanitation variable $(\overline{O D})$ to be defined at the theoretically relevant level of the neighborhood. This instrumentation strategy also addresses potential measurement error problems that could otherwise attenuate our estimates. Note that equations (4) and (5) do not include controls for own open defecation. Own OD

\footnotetext{
${ }^{39}$ To the extent that households which defecate in the open are larger than households which practice sanitary feces disposal, this will be an underestimate of exposure to fecally transmitted diseases.
} 
can be a significant share of $\overline{O D}_{p r t}^{P S U}$ for smaller PSUs, so that a change in $\overline{O D}_{r t}$ generates a less than a one-for-one change in $\overline{O D}_{p r t}^{P S U}$, mechanically shrinking the first stage and therefore inflating the IV estimates.

Table A8 reports results from the IV approach. Panel A reports effects instrumenting for PSUlevel open defecation with $\overline{O D}_{r t}$. First stage results for the IV analysis are reported in Panel B. The IV results are statistically indistinct from the corresponding estimates in Table 2.

\section{A.3 Inference Under Alternative Clustering}

For the main results in Table 2, we cluster standard errors at the level of the PSU. The difference-indifferences analysis in columns 4 through 6 uses variation in mean open defecation at the level of the region-by-year. Therefore, as an alternative to the PSU-level clustering, we present inference using clustering at the geographically more aggregated levels of the region-by-year and region.

Appendix Table A4 lists p-values for our coefficient estimates for each of the following clustering alternatives: by PSU (538 clusters), by region $\times$ year (50 clusters), and by region ( 25 clusters). As Cameron and Miller (2015) discuss, standard clustering techniques tend to over-reject the null for small numbers of clusters. "Small" is generally considered to be less than 50 (see, e.g., Cameron, Gelbach and Miller, 2008 and Bertrand et al., 2004). Therefore, we follow the Wild Cluster Bootstrap methodology of Cameron and Miller (2015), which incorporates an asymptotic refinement to address this issue. ${ }^{40}$ The bottom five rows of Appendix Table A4 report a complete set of p-values based on the three alternative levels of clustering, and include results generated by both standard and Wild Cluster Bootstrap methods. In 13 of 15 cases, the p-values are $\leq 0.05$, and in many cases they are $\leq 0.01$.

Finally, Table 3 complements this clustering analysis by taking a completely separate approach to statistical inference. We collapse the data to 25 observations and regress within-region mean differences in hemoglobin on within-region mean differences in open defecation over the 2006-2011 study period. These regression results, which are statistically significant at $p<.01$, are not subject to the clustering issue discussed above. Robust standard errors in Table 3 are consistent without asymptotic refinement. (Intuitively, these 25-observation regressions coarsen the data to the maximal possible extent.)

\footnotetext{
${ }^{40}$ Each of the Wild Cluster Bootstrap calculations in the table is generated by 5000 draws.
} 
Figure A1: Cross-Country Relationships: Hemoglobin versus Diet and Malaria

(A) Malaria

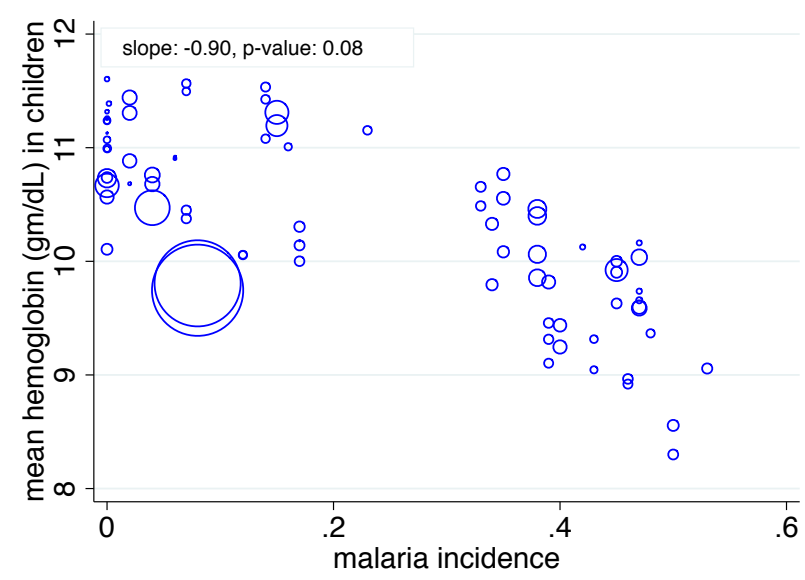

(C) Fruits and Vegetables

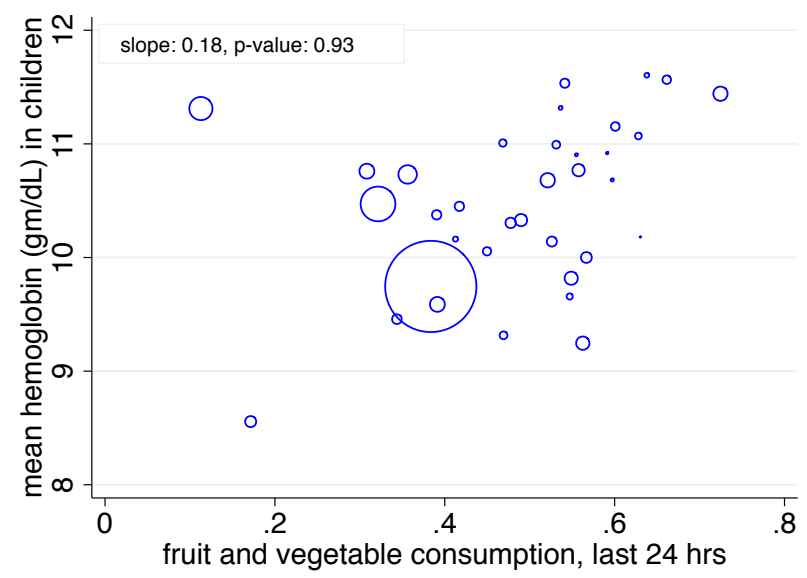

(B) Meat and Eggs

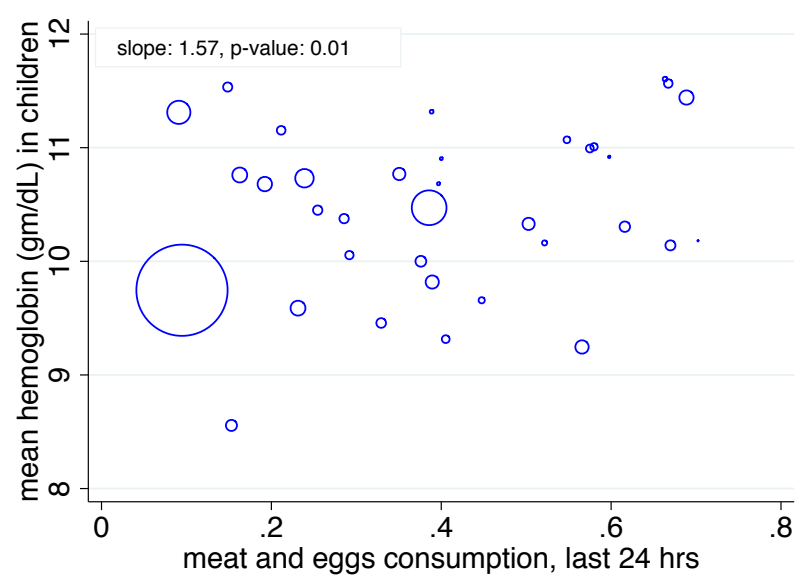

(D) Dietary Diversity

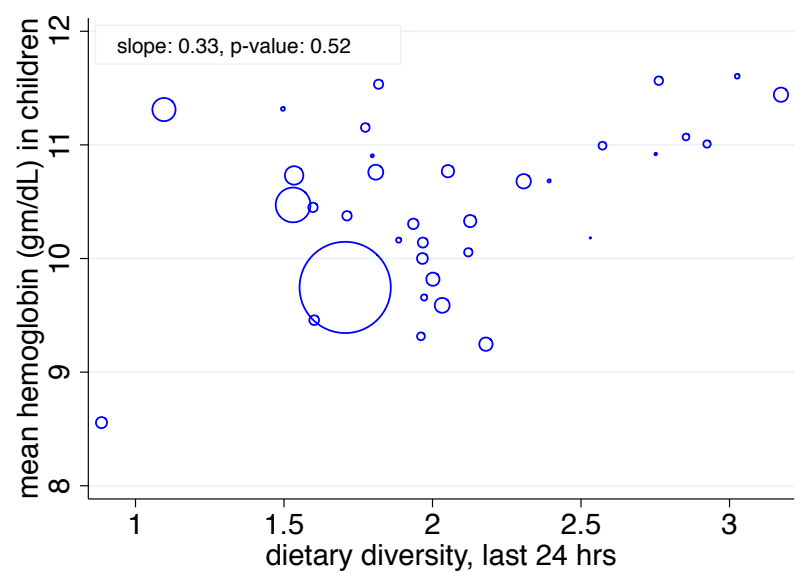

Note: Figure shows the cross-country relationship between diet variables and malaria infection rates and hemoglobin levels in children aged 6 to 35 months. Each point in the scatterplots corresponds to a country $\times$ year mean of a Demographic and Health Survey. Marker sizes are proportional to country populations. The 81 DHS surveys represented in Panel A are listed in Appendix Table A1. For panels B through D, only the 35 DHS surveys that collected information on the food consumption variables are included. In Panel B the horizontal axis measures the fraction of children consuming meat or eggs in the 24 hours before the survey. In Panel $C$ the horizontal axis measures the fraction of children consuming fruit/vegetables in the 24 hours before the survey. In Panel D the horizontal axis measures the number of different kinds of foods consumed by the child in the 24 hours before the survey. 
Table A1: Demographic and Health Surveys Used in Figure 1

\begin{tabular}{|c|c|c|c|}
\hline sub-Saharan Africa & & East Asia & \\
\hline Angola & 2006 & Cambodia & 2000 \\
\hline Angola & 2011 & Cambodia & 2005 \\
\hline Benin & 2001 & Cambodia & 2010 \\
\hline Benin & 2006 & Timor-Leste & 2009 \\
\hline Burkina Faso & 2003 & & \\
\hline Burkina Faso & 2010 & Europe & \\
\hline Burundi & 2010 & Albania & 2008 \\
\hline Cameroon & 2004 & Armenia & 2000 \\
\hline Cameroon & 2011 & Armenia & 2005 \\
\hline Congo (Brazzaville) & 2005 & Moldova & 2005 \\
\hline DRC & 2007 & Ukraine & 2011 \\
\hline Ethiopia & 1997 & & \\
\hline Ethiopia & 2003 & Latin America & \\
\hline Ghana & 2003 & Bolivia & 1998 \\
\hline Ghana & 2008 & Bolivia & 2003 \\
\hline Guinea & 2005 & Bolivia & 2008 \\
\hline Lesotho & 2004 & Guyana & 2009 \\
\hline Lesotho & 2009 & Haiti & 2000 \\
\hline Liberia & 2008 & Haiti & 2005 \\
\hline Liberia & 2011 & Honduras & 2005 \\
\hline Madagascar & 2003 & Peru & 1996 \\
\hline Madagascar & 2008 & Peru & 2000 \\
\hline Madagascar & 2011 & Peru & 2003 \\
\hline Malawi & 2004 & & \\
\hline Malawi & 2010 & North Africa & \\
\hline Malawi & 2012 & Egypt & 2005 \\
\hline Mali & 2001 & & \\
\hline Mali & 2006 & South Asia & \\
\hline Mozambique & 2011 & Bangladesh & 2011 \\
\hline Niger & 2006 & India & 1998 \\
\hline Rwanda & 2005 & India & 2005 \\
\hline Rwanda & 2007 & Nepal & 2006 \\
\hline Rwanda & 2010 & Nepal & 2011 \\
\hline Sao Tome and Principe & 2008 & & \\
\hline Senegal & 2005 & West Asia & \\
\hline Senegal & 2008 & Azerbaijan & 2006 \\
\hline Senegal & 2010 & Jordan & 2002 \\
\hline Sierra Leone & 2008 & Jordan & 2007 \\
\hline Swaziland & 2006 & Jordan & 2009 \\
\hline Tanzania & 2004 & Kazakhstan & 1995 \\
\hline Tanzania & 2007 & Kazakhstan & 1999 \\
\hline Tanzania & 2009 & Kyrgyz Republic & 1997 \\
\hline Tanzania & 2011 & Uzbekistan & 1996 \\
\hline Uganda & 2000 & & \\
\hline Uganda & 2006 & & \\
\hline Uganda & 2009 & & \\
\hline Zimbabwe & 2005 & & \\
\hline Zimbabwe & 2010 & & \\
\hline
\end{tabular}

Note: Table lists the country-year observations used in Figure 1. Data on childrens' hemoglobin and household open defecation within these 81 Demographic and Health Surveys were collapsed to country-year means. The surveys included cover 45 countries and span 18 years, $1995-2012$. 
Table A2: Summary Statistics for Subsample of Last-Born Children

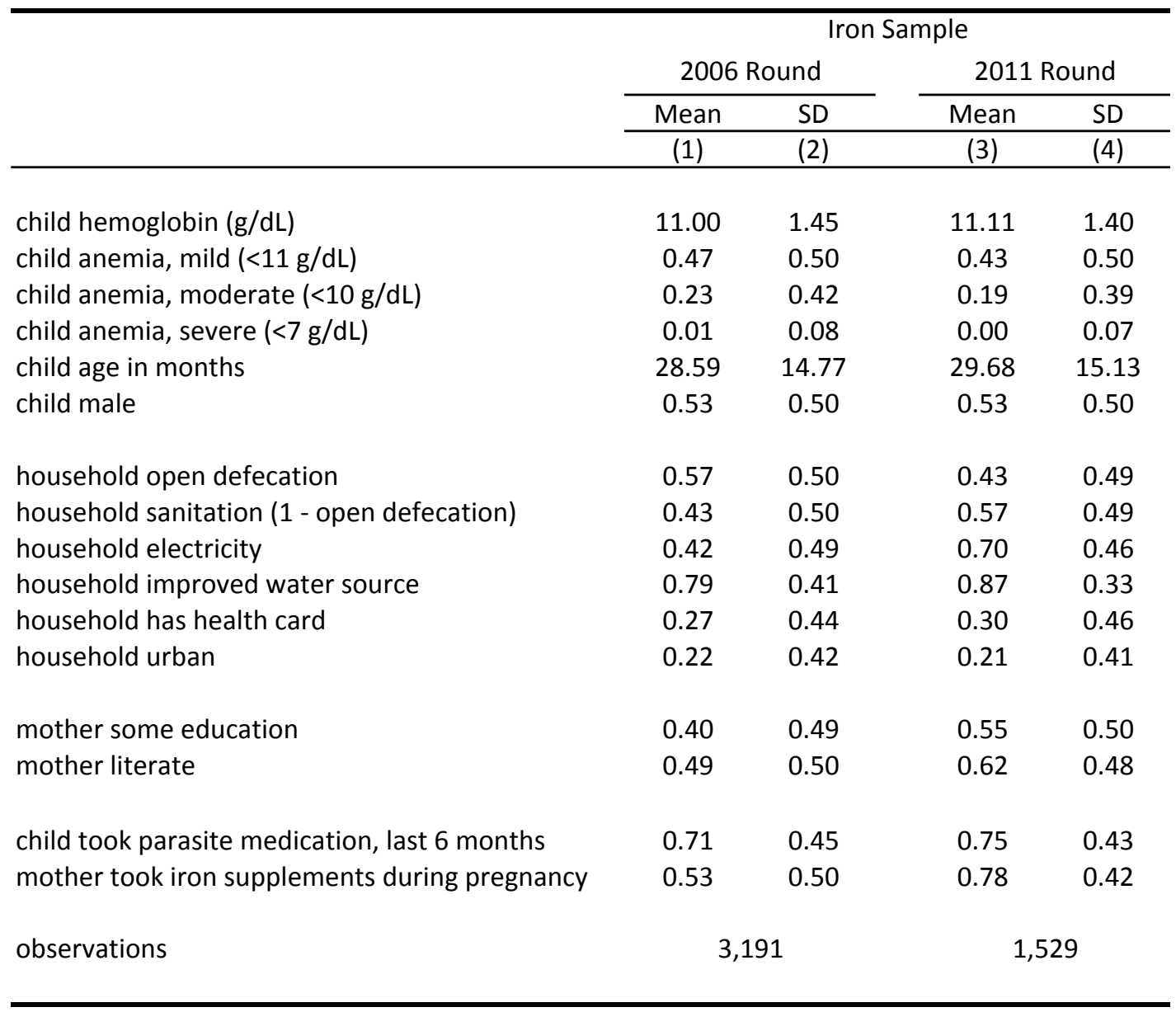

Note: Table displays summary statistics for the 2006 and 2011 rounds of the Nepal Demographic and Health Survey (DHS), calculated over the subsample of children who were the last children in the data born to their mothers (i.e. no older siblings). This is the sample for which information was collected on the mother's use of iron supplementation during pregnancy. See Table 1 for additional notes. 
Table A3: Regressions Corresponding to Figure 3 and to the Table 3 First Stage

Dependent variable:

Change in Mean OD within Region, 2006 to 2011

\begin{tabular}{|c|c|c|c|c|}
\hline \multirow{3}{*}{ Sample: } & \multicolumn{2}{|c|}{ Figure 3 Regressions } & \multicolumn{2}{|c|}{ IV First Stage (Table 3) } \\
\hline & Rural Only & Urban Only & Full & Full \\
\hline & $(1)$ & $(2)$ & (3) & $(4)$ \\
\hline Exposure (Region mean OD in 2006) & $\begin{array}{c}-0.45^{* *} \\
(0.13)\end{array}$ & $\begin{array}{c}-0.45^{* *} \\
(0.10)\end{array}$ & $\begin{array}{c}-0.27 * * \\
(0.07)\end{array}$ & $\begin{array}{c}-0.46 * * \\
(0.09)\end{array}$ \\
\hline Urban & & & & $x$ \\
\hline Change in mean electrification within region & & & & $x$ \\
\hline Change in mean improved water source within region & & & & $x$ \\
\hline F-stat & 12.4 & 19.9 & 16.3 & 25.3 \\
\hline Observations & 13 & 12 & 25 & 25 \\
\hline
\end{tabular}

Note: Table reports results from a series of OLS regressions in which the dependent variable is the change in mean open defecation within the region from 2006 to 2011. Columns 1 and 2 correspond to Figure 3 . Columns 3 and 4 comprise the first stage of the IV analysis in Table 3. Observations are regions. Robust standard errors are displayed. $+p<0.1,{ }^{*} p<0.05,{ }^{* *} p<0.01$. 
Table A4: Alternative Standard Errors for Coefficients in Columns 4-6 of Table 2

\begin{tabular}{|c|c|c|c|}
\hline \multirow{4}{*}{$\begin{array}{l}\text { Dependent variable: } \\
\text { Specification: }\end{array}$} & \multicolumn{3}{|c|}{ Hemoglobin $(\mathrm{g} / \mathrm{dL})$} \\
\hline & \multicolumn{3}{|c|}{ D-in-D } \\
\hline & $\mathrm{T} 2-\mathrm{Col} 4$ & $\mathrm{~T} 2-\mathrm{Col} 5$ & T2- Col 6 \\
\hline & $(1)$ & $(2)$ & (3) \\
\hline \multirow[t]{2}{*}{ Region mean OD } & $-1.53 * *$ & $-1.19 *$ & $-1.27^{*}$ \\
\hline & $(0.49)$ & $(0.48)$ & $(0.50)$ \\
\hline Survey round FEs & $x$ & $x$ & $\mathrm{x}$ \\
\hline Age-in-month $X$ sex indicators & $x$ & $x$ & $x$ \\
\hline Own OD & & $x$ & $x$ \\
\hline Economic controls & & & $x$ \\
\hline Mother education controls & & & $x$ \\
\hline Parasite medicine & & & $x$ \\
\hline Time-varying region controls & & & $x$ \\
\hline Region FEs & $x$ & $x$ & $x$ \\
\hline Mean of dependent variable & 11.2 & 11.2 & 11.2 \\
\hline Observations & 6,464 & 6,464 & 6,464 \\
\hline \multicolumn{4}{|l|}{ Alternative $p$-values } \\
\hline 1. Standard clustering by PSU (538 clusters) & $<0.01$ & 0.02 & 0.01 \\
\hline 2. Standard clustering by region $\mathrm{X}$ year (50 clusters) & $<0.01$ & $<0.01$ & $<0.01$ \\
\hline 3. Wild Cluster Bootstrap by region X year ( 50 clusters) & 0.01 & 0.03 & 0.08 \\
\hline 4. Standard clustering by region ( 25 clusters) & $<0.01$ & $<0.01$ & $<0.01$ \\
\hline 5. Wild Cluster Bootstrap by region ( 25 clusters) & 0.01 & 0.05 & 0.13 \\
\hline
\end{tabular}

Note: Table reports results from a series of OLS regressions. The dependent variable in all columns is the child's hemoglobin level. Controls are as described in the Table 2 notes. Observations are children. Standard errors shown in parentheses are clustered at the PSU level. p-values associated with clustering at alternative levels of aggregation are displayed in the last five rows of the table. We follow the Wild Cluster Bootstrap methodology of Cameron and Miller (2015) in rows labeled 3 and 5, which incorporates an asymptotic refinement. Each of the Wild Cluster Bootstrap calculations in the table is generated by 5000 repetitions. 
Table A5: Main Results Repeated with Binary Anemia Measures

\begin{tabular}{|c|c|c|c|c|c|c|}
\hline \multirow{4}{*}{$\begin{array}{l}\text { Dependent variable: } \\
\text { Specification: } \\
\text { Sample: }\end{array}$} & \multicolumn{2}{|c|}{$\begin{array}{l}\text { Anemia, } \\
\text { Mild or Worse } \\
(<11 \mathrm{~g} / \mathrm{dL})\end{array}$} & \multicolumn{2}{|c|}{$\begin{array}{c}\text { Anemia, } \\
\text { Moderate or Worse } \\
(<10 \mathrm{~g} / \mathrm{dL})\end{array}$} & \multicolumn{2}{|c|}{$\begin{array}{l}\text { Anemia, } \\
\text { Severe } \\
(<7 \mathrm{~g} / \mathrm{dL})\end{array}$} \\
\hline & Cross-Sec. & D-in-D & Cross-Sec. & D-in-D & Cross-Sec. & D-in-D \\
\hline & Full & Full & Full & Full & Full & Full \\
\hline & $(1)$ & (2) & (3) & (4) & (5) & (6) \\
\hline Region mean OD & $\begin{array}{c}0.189 * * \\
(0.072)\end{array}$ & $\begin{array}{c}0.220 \\
(0.161)\end{array}$ & $\begin{array}{c}0.182 * * \\
(0.053)\end{array}$ & $\begin{array}{c}0.382 * * \\
(0.108)\end{array}$ & $\begin{array}{l}0.011+ \\
(0.007)\end{array}$ & $\begin{array}{c}0.021 \\
(0.017)\end{array}$ \\
\hline Survey round FEs & $x$ & $x$ & $\mathrm{x}$ & $x$ & $x$ & $\mathrm{x}$ \\
\hline Age-in-month $X$ sex indicators & $x$ & $x$ & $x$ & $x$ & $x$ & $x$ \\
\hline Own OD & $x$ & $x$ & $x$ & $x$ & $x$ & $x$ \\
\hline Economic controls & $x$ & $x$ & $x$ & $x$ & $x$ & $\mathrm{x}$ \\
\hline Mother education controls & $x$ & $x$ & $\mathrm{x}$ & $x$ & $\mathrm{x}$ & $x$ \\
\hline Food and medicine controls & $x$ & $x$ & $x$ & $x$ & $x$ & $x$ \\
\hline Time-varying region controls & $x$ & $x$ & $x$ & $x$ & $x$ & $x$ \\
\hline Region FEs & & $x$ & & $x$ & & $x$ \\
\hline Mean of dependent variable & 0.42 & 0.42 & 0.19 & 0.19 & 0.01 & 0.01 \\
\hline Observations & 6,464 & 6,464 & 6,464 & 6,464 & 6,464 & 6,464 \\
\hline
\end{tabular}

Note: Table reports results from OLS regressions that repeat specifications from Table 2 with alternative dependent variables. Here, the dependent variables are indicators for anemia (blood hemoglobin below a threshold level) in place of the continuous hemoglobin measure. The three binary measures indicated at the column headers correspond to the World Health Organization standard thresholds for mild $(<11 \mathrm{~g} / \mathrm{dL})$, moderate $(<10 \mathrm{~g} / \mathrm{dL})$, and severe $(<7 \mathrm{~g} / \mathrm{dL})$ anemia. The specifications in columns 1,3 , and 5 match the specification in column 3 of Table 2 . The specifications in columns 2, 4, and 6 match the specification in column 6 of Table 2. See the Table 2 notes for additional information. Observations are children. Standard errors are clustered at the PSU level. $+p<0.1$, $^{*} p<0.05$, ** $p<0.01$. 
Table A6: Main Results Replicated in the Subsample of Children for Whom Nutrition Data Were Collected

\begin{tabular}{|c|c|c|c|c|c|c|c|c|}
\hline \multirow{3}{*}{$\begin{array}{l}\text { Dependent variable: } \\
\text { Specification: } \\
\text { Sample: }\end{array}$} & \multicolumn{8}{|c|}{ Hemoglobin $(\mathrm{g} / \mathrm{dL})$} \\
\hline & \multicolumn{2}{|c|}{ Pooled Cross-Section } & \multicolumn{2}{|c|}{ D-in-D } & \multicolumn{2}{|c|}{ Pooled Cross-Section } & \multicolumn{2}{|c|}{ D-in-D } \\
\hline & $\begin{array}{c}\text { Food } \\
(1) \\
\end{array}$ & $\begin{array}{c}\text { Food } \\
(2)\end{array}$ & $\begin{array}{c}\text { Food } \\
(3)\end{array}$ & $\begin{array}{c}\text { Food } \\
(4)\end{array}$ & $\begin{array}{c}\text { Iron } \\
(5) \\
\end{array}$ & $\begin{array}{c}\text { Iron } \\
(6) \\
\end{array}$ & $\begin{array}{l}\text { Iron } \\
(7) \\
\end{array}$ & $\begin{array}{c}\text { Iron } \\
(8) \\
\end{array}$ \\
\hline Region mean OD & $\begin{array}{c}-1.01^{* *} \\
(0.18)\end{array}$ & $\begin{array}{c}-0.92^{* *} \\
(0.26)\end{array}$ & $\begin{array}{r}-1.28^{*} \\
(0.58)\end{array}$ & $\begin{array}{l}-1.08+ \\
(0.57)\end{array}$ & $\begin{array}{c}-1.02^{* *} \\
(0.17)\end{array}$ & $\begin{array}{c}-1.03^{* *} \\
(0.25)\end{array}$ & $\begin{array}{c}-2.06^{* *} \\
(0.47)\end{array}$ & $\begin{array}{r}-1.75^{* *} \\
(0.48)\end{array}$ \\
\hline Parasite medication & $\begin{array}{l}0.11+ \\
(0.06)\end{array}$ & $\begin{array}{c}0.00 \\
(0.06)\end{array}$ & $\begin{array}{c}0.05 \\
(0.06)\end{array}$ & $\begin{array}{c}0.03 \\
(0.06)\end{array}$ & $\begin{array}{l}0.10+ \\
(0.05)\end{array}$ & $\begin{array}{l}-0.01 \\
(0.05)\end{array}$ & $\begin{array}{c}0.03 \\
(0.05)\end{array}$ & $\begin{array}{c}0.01 \\
(0.05)\end{array}$ \\
\hline $\begin{array}{l}\text { Mother iron supplements } \\
\text { during pregnancy }\end{array}$ & & & & & $\begin{array}{l}-0.04 \\
(0.05)\end{array}$ & $\begin{array}{l}-0.02 \\
(0.05)\end{array}$ & $\begin{array}{l}0.08+ \\
(0.04)\end{array}$ & $\begin{array}{l}-0.02 \\
(0.05)\end{array}$ \\
\hline Dietary diversity & $\begin{array}{l}0.06+ \\
(0.03)\end{array}$ & $\begin{array}{l}0.03 \\
(0.03)\end{array}$ & $\begin{array}{l}0.04 \\
(0.03)\end{array}$ & $\begin{array}{l}0.02 \\
(0.03)\end{array}$ & & & & \\
\hline Fruit and Vegetables, last $24 \mathrm{hrs}$ & $\begin{array}{l}-0.02 \\
(0.07)\end{array}$ & $\begin{array}{l}-0.01 \\
(0.06)\end{array}$ & $\begin{array}{l}0.00 \\
(0.06)\end{array}$ & $\begin{array}{l}0.01 \\
(0.06)\end{array}$ & & & & \\
\hline Meat and Eggs, last $24 \mathrm{hrs}$ & $\begin{array}{l}-0.08 \\
(0.07)\end{array}$ & $\begin{array}{l}-0.01 \\
(0.06)\end{array}$ & $\begin{array}{l}-0.02 \\
(0.06)\end{array}$ & $\begin{array}{c}0.00 \\
(0.06)\end{array}$ & & & & \\
\hline Meal count, last $24 \mathrm{hrs}$ & & & & & & & & \\
\hline 1 meal & $\begin{array}{c}0.16 \\
(0.24)\end{array}$ & $\begin{array}{c}0.01 \\
(0.23)\end{array}$ & $\begin{array}{c}0.06 \\
(0.22)\end{array}$ & $\begin{array}{c}0.00 \\
(0.21)\end{array}$ & & & & \\
\hline 2 meals & $\begin{array}{l}-0.01 \\
(0.14)\end{array}$ & $\begin{array}{l}-0.16 \\
(0.14)\end{array}$ & $\begin{array}{l}-0.16 \\
(0.13)\end{array}$ & $\begin{array}{l}-0.16 \\
(0.13)\end{array}$ & & & & \\
\hline 3 meals & $\begin{array}{c}0.01 \\
(0.13)\end{array}$ & $\begin{array}{l}-0.13 \\
(0.14)\end{array}$ & $\begin{array}{l}-0.15 \\
(0.13)\end{array}$ & $\begin{array}{l}-0.16 \\
(0.13)\end{array}$ & & & & \\
\hline 4 meals & $\begin{array}{c}0.12 \\
(0.14)\end{array}$ & $\begin{array}{l}-0.05 \\
(0.14)\end{array}$ & $\begin{array}{l}-0.02 \\
(0.13)\end{array}$ & $\begin{array}{l}-0.06 \\
(0.14)\end{array}$ & & & & \\
\hline 5 meals & $\begin{array}{c}0.00 \\
(0.15)\end{array}$ & $\begin{array}{l}-0.12 \\
(0.16)\end{array}$ & $\begin{array}{l}-0.09 \\
(0.15)\end{array}$ & $\begin{array}{l}-0.13 \\
(0.15)\end{array}$ & & & & \\
\hline 6 meals & $\begin{array}{c}0.10 \\
(0.17)\end{array}$ & $\begin{array}{l}-0.04 \\
(0.17)\end{array}$ & $\begin{array}{c}0.04 \\
(0.16)\end{array}$ & $\begin{array}{l}-0.04 \\
(0.16)\end{array}$ & & & & \\
\hline 7 meals & $\begin{array}{c}0.07 \\
0.190\end{array}$ & $\begin{array}{c}0.00 \\
0.190\end{array}$ & $\begin{array}{c}0.02 \\
0.180\end{array}$ & $\begin{array}{l}-0.06 \\
0.190\end{array}$ & & & & \\
\hline Survey round FEs & $\mathrm{x}$ & $\mathrm{x}$ & $\mathrm{x}$ & $\mathrm{x}$ & $\mathrm{x}$ & $\mathrm{x}$ & $\mathrm{x}$ & $\mathrm{x}$ \\
\hline Age-in-month $X$ sex indicators & $\mathrm{x}$ & $\mathrm{x}$ & $\mathrm{x}$ & $\mathrm{x}$ & $\mathrm{x}$ & $\mathrm{x}$ & $\mathrm{x}$ & $\mathrm{x}$ \\
\hline Own OD & & $\mathrm{x}$ & & $\mathrm{x}$ & & $\mathrm{x}$ & & $\mathrm{x}$ \\
\hline Economic controls & & $\mathrm{x}$ & & $\mathrm{x}$ & & $\mathrm{x}$ & & $\mathrm{x}$ \\
\hline Mother education controls & & $\mathrm{x}$ & & $\mathrm{x}$ & & $\mathrm{x}$ & & $\mathrm{x}$ \\
\hline Time-varying region controls & & $\mathrm{x}$ & & $\mathrm{x}$ & & $\mathrm{x}$ & & $\mathrm{x}$ \\
\hline Region FEs & & $\mathrm{x}$ & $\mathrm{x}$ & $\mathrm{x}$ & & $\mathrm{x}$ & $\mathrm{x}$ & $\mathrm{x}$ \\
\hline Mean of dependent variable & 11.0 & 11.0 & 11.0 & 11.0 & 11.0 & 11.0 & 11.0 & 11.0 \\
\hline Observations & 4,348 & 4,348 & 4,348 & 4,348 & 4,720 & 4,720 & 4,720 & 4,720 \\
\hline
\end{tabular}

Note: Table reports results from a series of OLS regressions. The results are robust to the inclusion of controls for food intake and a control for mother's use of iron supplements during the child's in utero period. The dependent variable in all columns is the child's hemoglobin level. Food controls include an indicator for the consumption of fruits and vegetables within the last 24 hours, an indicator for the consumption of meat and eggs within the last 24 hours, the count of different kinds of foods consumed in the last 24 hours (dietary diversity), and the number of meals (8 categories as indicators, zero meals as the omitted category) within the last 24 hours. Other controls are as described in the Table 2 notes. Observations are children. Standard errors are clustered at the PSU level. $+p<0.1,{ }^{*} p<0.05,{ }^{* *} p<0.01$. 
Table A7: Parallel Trends: Other Changes in Development Indicators are Uncorrelated with Sanitation Improvement Across-Time, Within-Region

\begin{tabular}{|c|c|c|c|}
\hline \multirow[t]{2}{*}{ Dependent variable: } & \multicolumn{3}{|c|}{ Change in Region Mean of: } \\
\hline & $\begin{array}{l}\text { Household } \\
\text { Electrification }\end{array}$ & $\begin{array}{c}\text { Access to } \\
\text { Improved } \\
\text { Water Source }\end{array}$ & $\begin{array}{l}\text { Family Has } \\
\text { Health Card }\end{array}$ \\
\hline Specification: & OLS & OLS & OLS \\
\hline & $(1)$ & $(2)$ & $(3)$ \\
\hline Change in mean OD within region & $\begin{array}{c}0.16 \\
(0.30)\end{array}$ & $\begin{array}{l}-0.21 \\
(0.25)\end{array}$ & $\begin{array}{l}-0.15 \\
(0.10)\end{array}$ \\
\hline Observations (regions) & 25 & 25 & 25 \\
\hline
\end{tabular}

Note: Table reports results from a series of OLS regressions. The dependent variables are listed in the column headers and are changes over time in regional means of: household electrification; household access to "improved" water sources, where "improved" is defined by the World Bank and UNICEF's Joint Monitoring Programme. Improved water sources include piped water, protected wells, and protected springs; and household possession of a national health card. The sole regressor in each column is the change in regional mean open defecation $\left(\Delta \overline{O D}_{r t}\right)$. Observations are the 25 regions, defined by 13 geographic areas interacted with an urban indicator. Robust standard errors are displayed. $+p<0.1{ }^{*} p<0.05,{ }^{* *} p<0.01$. 
Table A8: IV Results

\begin{tabular}{|c|c|c|}
\hline \multirow{4}{*}{$\begin{array}{l}\text { Dependent variable: } \\
\text { Specification: } \\
\text { Sample: }\end{array}$} & \multicolumn{2}{|c|}{ Hemoglobin $(\mathrm{g} / \mathrm{dL})$} \\
\hline & \multicolumn{2}{|c|}{ IV } \\
\hline & Full & Full \\
\hline & (1) & $(2)$ \\
\hline \multicolumn{3}{|l|}{ Panel A: IV Regression } \\
\hline PSU mean OD & $\begin{array}{c}-1.51^{* *} \\
(0.52)\end{array}$ & $\begin{array}{c}-1.63 * * \\
(0.61)\end{array}$ \\
\hline \multicolumn{3}{|c|}{ Panel B: Correponding First Stage Regression } \\
\hline Region mean OD & $\begin{array}{l}1.01^{* *} \\
(0.25)\end{array}$ & $\begin{array}{c}0.90 * * \\
(0.21)\end{array}$ \\
\hline Survey round FEs & $\mathrm{X}$ & $X$ \\
\hline Age-in-month $X$ sex indicators & $x$ & $x$ \\
\hline \multicolumn{3}{|l|}{ Own OD } \\
\hline Economic controls & & $\mathrm{X}$ \\
\hline Mother education controls & & $x$ \\
\hline Parasite medicine & & $x$ \\
\hline Time-varying region controls & & $x$ \\
\hline Region FEs & $\mathrm{X}$ & $x$ \\
\hline Mean of dependent variable & 11.2 & 11.2 \\
\hline First stage F-stat & 16.7 & 19.2 \\
\hline Observations & 6,464 & 6,464 \\
\hline
\end{tabular}

Note: Table reports results from IV regressions that instrument for PSU-level mean open defecation $\left(\overline{O D}_{p r t}^{P S U}\right)$ with regional mean open defecation $\left(\overline{O D}_{r t}\right)$. Panel A reports the IV results, and Panel B reports the corresponding first stages. Controls are as described in the Table 2 notes. Observations are children. Standard errors are clustered at the PSU level. + $p<0.1,^{*} p<0.05,{ }^{* *} p<0.01$. 